\title{
eNeuro
}

Research Article: New Research / Neuronal Excitability

\section{Kinetics and connectivity properties of Parvalbumin- and Somatostatin-positive inhibition in layer $2 / 3$ medial entorhinal cortex}

https://doi.org/10.1523/ENEURO.0441-21.2022

Cite as: eNeuro 2022; 10.1523/ENEURO.0441-21.2022

Received: 18 October 2021

Revised: 14 January 2022

Accepted: 22 January 2022

This Early Release article has been peer-reviewed and accepted, but has not been through the composition and copyediting processes. The final version may differ slightly in style or formatting and will contain links to any extended data.

Alerts: Sign up at www.eneuro.org/alerts to receive customized email alerts when the fully formatted version of this article is published. 4.0 International license, which permits unrestricted use, distribution and reproduction in any medium provided that the original work is properly attributed. 
1

3

\section{Manuscript Title:}

Kinetics and connectivity properties of Parvalbumin- and Somatostatin-positive inhibition in layer 2/3 medial entorhinal cortex

\section{Abbreviated Title:}

Inhibitory connectivity in mEC

\section{List of Authors:}

Fernando R. Fernandez ${ }^{1}$, Guillem Via², Carmen C. Canavier², and John A. White ${ }^{1}$

${ }^{1}$ Department of Biomedical Engineering, Center for Systems Neuroscience, Neurophotonics Center, Boston University 610 Commonwealth Avenue, Boston, MA, USA 02215

${ }^{2}$ Louisiana State University Health Sciences Center, Department of Cell Biology and Anatomy, 18 New Orleans, LA, 70112

\section{Author Contributions:}

FRF Designed Research, Performed Research, Analyzed Data, Wrote Paper GV Designed Research, Performed Research, Analyzed Data CCC Designed Research, Wrote Paper JAW Designed Research, Wrote Paper

\section{Correspondence:}

fernrf@gmail.com

6. Number of Figures: 9

7. Number of Tables: 1

8. Number of Multimedia: 0

9. Number of Words for Abstract: 250

10. Number of Words for Significance: 101

11. Number of Words for Introduction: 521

12. Number of Words for Discussion: 1381

13. Acknowledgements: None

14. Conflict of Interest: No (Authors report no conflict of interest)

15. Funding

Sources:

Ro1NSo54281. 


\title{
Kinetics and connectivity properties of Parvalbumin- and Somatostatin- positive inhibition in layer $2 / 3$ medial entorhinal cortex
}

\author{
Fernando R. Fernandez ${ }^{1}$, Guillem Via ${ }^{2}$, Carmen C. Canavier ${ }^{2}$, and John A. White ${ }^{1}$ \\ ${ }^{1}$ Department of Biomedical Engineering, Center for Systems Neuroscience, Neurophotonics \\ Center, Boston University \\ 610 Commonwealth Avenue, Boston, MA, USA 02215 \\ ${ }^{2}$ Louisiana State University Health Sciences Center, Department of Cell Biology and Anatomy, \\ 18 New Orleans, LA, 70112
}

Parvalbumin $\left(\mathrm{Pvalb}^{+}\right)$- and somatostatin $\left(\mathrm{Sst}^{+}\right)$-positive cells are the two largest subgroups of inhibitory interneurons. Studies in visual cortex indicate that synaptic connections between $\mathrm{Pvalb}^{+}$cells are common while connections between $\mathrm{Sst}^{+}$interneurons have not been observed. The inhibitory connectivity and kinetics of these two interneuron subpopulations, however, have not been characterized in medial entorhinal cortex (mEC). Using fluorescence-guided paired recordings in mouse brain slices from interneurons and excitatory cells in layer $2 / 3 \mathrm{mEC}$, we found that, unlike neocortical measures, $\mathrm{Sst}^{+}$cells inhibit each other, albeit with a lower probability than $\mathrm{Pvalb}^{+}$cells (18\% versus $36 \%$ for unidirectional connections). Gap junction connections were also more frequent between $\mathrm{Pvalb}^{+}$cells than between $\mathrm{Sst}^{+}$cells. $\mathrm{Pvalb}^{+}$cells inhibited each other with larger conductances, smaller decay time constants and shorter delays. Similarly, synaptic connections between $\mathrm{Pvalb}^{+}$and excitatory cells were more likely and expressed faster decay times and shorter delays than those between $\mathrm{Sst}^{+}$and excitatory cells. Inhibitory cells exhibited smaller synaptic decay time constants between interneurons than on their excitatory targets. Inhibition between interneurons also depressed faster, and to a greater extent. Finally, inhibition onto layer 2 pyramidal and stellate cells originating from Pvalb ${ }^{+}$ interneurons were very similar, with no significant differences in connection likelihood, inhibitory amplitude, and decay time. A model of short-term depression fitted to the data indicates that recovery time constants for refilling the available pool are in the range of 50-150 $\mathrm{ms}$ and that the fraction of the available pool released on each spike is in the range 0.2-0.5.

\section{Significance}

Two large and distinct classes of interneurons in medial entorhinal cortex (mEC) include parvalbumin $\left(\mathrm{Pvalb}^{+}\right)$- and somatostatin $\left(\mathrm{Sst}^{+}\right)$-positive cells. Previous work has demonstrated unique functions with regards to spatial tuning and network oscillations for these two interneuron populations. Potential differences in kinetics of inhibition and likelihood of connection from these two interneuron groups, however, have not been quantified. Here, using fluorescence to guide intracellular recordings, we quantified the synaptic connections from both types of interneurons. We indicate that $\mathrm{Sst}^{+}$and $\mathrm{Pvalb}^{+}$express different synaptic kinetics that 
are target-cell specific. In contrast to neocortical measures, we find substantial connections between $\mathrm{Sst}^{+}$interneurons.

Introduction

Medial entorhinal cortex (mEC) plays a significant role in spatial navigation (Burgalossi and Brecht, 2014; Sasaki et al., 2015). In layer 2/3 mEC, the neurophysiological correlates of this role are partially supported by spatially tuned cells ('grid cells') that generate spikes at the vertices of a hexagonal grid formed during an animal's movement (Fyhn et al., 2004; Hafting et al., 2005). The region also generates theta-nested gamma frequency oscillations (Colgin et al., 2009) that synchronize grid cell spiking to specific phases of a network-wide theta oscillation (Hafting et al., 2008; Reifenstein et al., 2012).

Both spatial tuning and oscillations in mEC are often accounted for using a canonical circuit composed of excitatory and inhibitory cells connected through recurrent excitation and negative feedback (Shipston-Sharman et al., 2016). In mEC, fast-firing interneurons participate in theta-nested gamma oscillations through a mechanism similar to pyramidal-interneuron gamma oscillations in cortex and hippocampus (Pastoll et al., 2013); by inhibiting stellate cells, these neurons set the phase of spiking and frequency of gamma oscillations during network activation. Fast-firing interneurons also provide the sole synaptic communication path between stellate cells, which lack recurrent excitatory connections (Couey et al., 2013; Pastoll et al., 2013) (but see (Fuchs et al., 2016)). In contrast, a subset of low threshold-spiking interneurons have been shown to suppress network oscillations in mEC (de Filippo et al., 2021). Further, in behaving animals, inhibition from layer $2 / 3$ parvalbumin $\left(\mathrm{Pvalb}^{+}\right)$- and somatostatin $\left(\mathrm{Sst}^{+}\right)$positive interneurons have separate roles in setting the spatial tuning and firing rates of layer 2 grid cells (Miao et al., 2017).

In cortex and hippocampus, $\mathrm{Pvalb}^{+}$and $\mathrm{Sst}^{+}$interneurons comprise two families of interneurons that, to a first approximation, correspond to fast-firing and low threshold-spiking interneurons, respectively (Rudy et al., 2011; Kepecs and Fishell, 2014; Tremblay et al., 2016; Pelkey et al., 2017). Across different regions, fast-acting, perisomatic-targeting inhibitory feedback typically originates from fast-firing, $\mathrm{Pvalb}^{+}$cells (Kawaguchi and Kubota, 1997, 1998; Kubota et al., 2016). These cells are highly interconnected through synapses and gap junctions (Bartos et al., 2002; Hjorth et al., 2009). Conversely, $\mathrm{Sst}^{+}$interneurons are more diverse electrophysiologically (Tremblay et al., 2016; Yavorska and Wehr, 2016), target dendrites (Kawaguchi and Kubota, 1998), can be electrical coupled (Amitai et al., 2002; Fanselow et al., 2008), and provide inhibition onto other, non-Sst ${ }^{+}$neurons, with little evidence of synaptic connections between $\mathrm{Sst}^{+}$cells (Pfeffer et al., 2013). Specifically, measures in visual cortex indicate a lack of synaptic connections between $\mathrm{Sst}^{+}$interneurons (Pfeffer et al., 2013).

To date, the likelihood and synaptic kinetics of inhibition from $\mathrm{Pvalb}^{+}$and $\mathrm{Sst}^{+}$ interneurons in $\mathrm{mEC}$ have not been measured. Although some properties are likely shared with other brain regions, significant differences have been observed between regions (Tremblay et al., 2016; Yavorska and Wehr, 2016). Measures in $\mathrm{mEC}$, therefore, can guide specific mechanisms and models of $\mathrm{mEC}$ activity with regards to the role of inhibition in spatial tuning and network synchrony. Using Cre-based expression of the tdTomato fluorophore, we targeted Pvalb $^{+}$and $\mathrm{Sst}^{+}$interneurons and used paired recordings from mouse slices to establish the properties of inhibition, both between interneurons, as well as onto excitatory cells, in layer $2 / 3 \mathrm{mEC}$. 


\section{Methods}

\section{Ethics statement}

All experimental protocols were approved by the Boston University Institutional Animal Care and Use Committee.

\section{Transgenic mice}

To target $\mathrm{Pvalb}^{+}$and $\mathrm{Sst}^{+}$interneurons, we used mice expressing the red fluorescent protein tdTomato in either interneuron population. For Pvalb ${ }^{+}$neurons, C57BL/6J background, PvalbCre mice (Taniguchi et al., 2011) (Jackson Labs, stock \# 017320) were crossed with the lox-stoplox tdTomato reporter mice (Zariwala et al., 2011)(Jackson Labs, stock \# 007914). The same reporter mouse was crossed to Sst-Cre mice (Taniguchi et al., 2011)(Jackson Labs, stock \# 013044) to visualize $\mathrm{Sst}^{+}$interneurons.

\section{Slice preparation}

Horizontal slices of entorhinal cortex and hippocampus were prepared from 2-8 month-old mice of either sex. After anesthetization with isoflurane and decapitation, brains were removed and immersed in $\mathrm{o}^{\circ} \mathrm{C}$ sucrose-substituted artificial cerebrospinal fluid (in $\mathrm{mM}$ ): sucrose (185), $\mathrm{KCl}$ (2.5), $\mathrm{NaH}_{2} \mathrm{PO}_{4}$ (1.25), $\mathrm{MgCl}_{2}$ (10), $\mathrm{NaHCO}_{3}$ (25), Glucose (12.5), $\mathrm{CaCl}_{2}$ (0.5). Slices were cut to a thickness of $400 \mu \mathrm{m}$ (Leica VT 1200 , Leica Microsystems). Slices were then incubated at $35^{\circ} \mathrm{C}$ for 20 minutes in artificial cerebrospinal fluid (ACSF) consisting of the following (in mM): $\mathrm{NaCl}$ (125), $\mathrm{NaHCO}_{3}$ (25), D-glucose (25), $\mathrm{KCl}(2), \mathrm{CaCl}_{2}$ (2), $\mathrm{NaH}_{2} \mathrm{PO}_{4}(1.25)$ and $\mathrm{MgCl}_{2}$ (1). Afterwards, slices were cooled to room temperature $\left(20{ }^{\circ} \mathrm{C}\right)$. After the incubation period, slices were moved to the stage of a two-photon imaging system (Thorlabs) with a modelocked Ti:Sapphire laser (Chameleon Ultra II; Coherent) set to wavelengths between $915 \mathrm{~nm}$ and $950 \mathrm{~nm}$, which was used to excite both the Alexa Fluor 488 and tdTomato using a 20X, NA 1.0 (Olympus) objective lens. Laser scanning was performed using resonant scanners and fluorescence was detected using two photo-multiplier tubes (Hamamatsu) equipped with red and green filters to separate emission from Alexa Fluor 488 and tdTomato. The stage of the microscope contained recirculating ASCF, with all recordings conducted between $34{ }^{\circ} \mathrm{C}$ and 36 ${ }^{\circ} \mathrm{C}$.

\section{Electrophysiology}

Electrodes were pulled using a horizontal puller (Sutter Instruments) using filament, thin-wall glass (Sutter Instruments). Intracellular pipette solution consisted of the following (in mM): Kgluconate (120), $\mathrm{KCl}(20)$, $\mathrm{HEPES}$ (10), diTrisPhCr (7), $\mathrm{Na}_{2} \mathrm{ATP}$ (4), $\mathrm{MgCl}_{2}$ (2), Tris-GTP (0.3), EGTA (0.2) and buffered to $\mathrm{pH} 7.3$ with $\mathrm{KOH}$. To visualize electrodes, the cyan-green fluorescent dye Alexa Fluor 488 hydrazide (Thermo Fisher Scientific) was added to the intracellular electrode solution (0.3\% weight/volume). To patch non-fluorescent, excitatory cells, we used a "shadow" patch technique (Kitamura et al., 2008) in which extracellular green fluorescence contrast with cells that do not fluorescence. Although this does not exclude the possibility of recording from interneurons, the values of spike half-width in probable excitatory cells indicated little overlap with those of $\mathrm{Pvalb}^{+}$and $\mathrm{Sst}^{+}$neurons.

Electrode resistances were between 4 and $7 \mathrm{M} \Omega$, with access resistance values between 15 and $38 \mathrm{M} \Omega$. Seal resistance values were always greater than $2 \mathrm{G} \Omega$. Capacitance was fully 
compensated in voltage clamp during the on-cell configuration prior to breaking into the cell. For current-clamp recordings, full bridge balance compensation was used. Series resistance compensation between $45-65 \%$ was used during voltage clamp recordings. Voltage trace signals were amplified and low-pass filtered at $10-20 \mathrm{kHz}$ before being digitized at $20-50 \mathrm{kHz}$. For current traces, signals were low pass filtered at $4 \mathrm{kHz}$. All electrophysiology was carried out using a Multiclamp 700B (Molecular Devices) and a Digidata 1550 (Molecular Devices). Liquid junction potentials were not corrected.

\section{Recording protocols}

A series of 1-second-long hyperpolarizing and depolarizing current pulses were used to generate spike frequency-current relationships. Spike half-width was taken from the first current pulse that generated spikes. Using the same data, the membrane decay time constant was acquired using an exponential fit to the voltage. To determine the presence of a synaptic connection, the post-synaptic cell was depolarized to $-40 \mathrm{mV}$, while driving the pre-synaptic cell with a brief (2 $\mathrm{ms}$ ), strong ( $>0.5 \mathrm{nA}$ ) pulse that drove a single spike. For measures of excitatory synaptic connections on interneurons, cells were voltage clamped at $-70 \mathrm{mV}$. For frequency-dependent synaptic depression measures, pulses were delivered at 5, 10, 20, 50, 100, and $200 \mathrm{~Hz}$. Synaptic current responses were averaged across 25-50 trials. For gap junction measures, a square pulse or spike was generated in the pre-synaptic cell and 25-50 trials averaged in the post-synaptic cell. A measured junction potential of $\sim 11 \mathrm{mV}$ was not subtracted from recordings. Recordings were taken from slices between $3.2 \mathrm{~mm}$ and $4.3 \mathrm{~mm}$ from the dorsal surface (bregma) of the brain.

\section{Data Analyses}

For current clamp analyses of spike shape, spike threshold was defined using the peak of the second derivative of the spike waveform. Spike half-width was taken as the width of the spike at voltages corresponding to the half amplitude (mid-point between spike peak amplitude and threshold). For time constant measures, a current pulse was used to depolarized cells to a value slightly below spike threshold. A single exponential decay function was used to fit the membrane voltage time course associated with hyperpolarization and the return to resting voltage resulting from the end of the current pulse.

Averaged individual post-synaptic current decay and rise time courses were fit with single exponential functions. Synaptic delay was measured as the time between spike threshold and the $10 \%$ rise time of the averaged synaptic current response. All peak amplitudes were taken as the peak of the averaged synaptic current response. In a subset of recordings, where individual responses were large, we compared the averaged response to the distribution across trials. In this data set, mean responses sat near the center of the trial-to-trial distribution, suggesting that averaging did not impact our estimates of rise kinetics and delays.

The probability of chemical synaptic connectivity was calculated assuming that the probability of connections in each direction between a pair of neurons were equal and independent.

\section{Statistical Analyses}

All values are presented as the mean along with the standard deviation. Normality of data points was established using a Shapiro-Wilk and Lilliefors test. A positive result $(\mathrm{p}<0.05)$ from either of these tests was used to determined normality and the use of non-parametric statistical tests noted in the Results section. For non-normally distributed data points, results are presented as the median along with the first $\left(Q_{1}\right)$ and third $\left(Q_{3}\right)$ quartile values. 


\section{Modeling}

The model by Markram and Tsodyks (1996) predicts the amplitude of inhibitory currents from a differential equation for the available fraction of transmitter $x$ that evolves according to: $\frac{d x}{d t}=\frac{1-x}{\tau_{r}}-U_{S E} x \delta\left(t-t_{s}\right)$, where $t_{s}$ is the spike time, $\tau_{r}$ is the recovery time to replenish the available pool of vesicles for release, $U_{S E}$ is the fraction of available pool released by each spike, and the value of $x$ prior to a spike is proportional to the peak current value of the IPSC. The solution to the differential equation between presynaptic spikes is $x(t)=1-\left(1-x_{i}\right) e^{-\frac{\left(\mathrm{t}-t_{s}\right)}{\tau_{r}}}$. However, there is a discontinuous decrement, $x$, by an amount $U_{S E} x$ after each spike so a discrete map from spike to spike is required: $x_{i}=1-\left(1-x_{i-1}\left(1-U_{S E}\right)\right) e^{\frac{-\left(t-t_{S}\right)}{\tau_{r}}}$ where $i$ denotes presynaptic spike number. Normalizing the spike amplitude so that the initial value of $x$ is 1 and substituting one over the frequency of the presynaptic spike train for $t-t_{s}$, we can write this recursively:

$$
x_{k}=\left(1-e^{-\frac{1}{f \tau_{r}}}\right) \frac{1-\left[\left(1-U_{S E}\right) e^{-\frac{1}{f \tau_{r}}}\right]^{k}}{1-\left(1-U_{S E}\right) e^{-\frac{1}{f \tau_{r}}}}+\left[\left(1-U_{S E}\right) e^{-\frac{1}{f \tau_{r}}}\right]^{k}
$$

We fit each experimental train of the normalized inhibitory peak amplitudes to the expression above by adjusting the two parameters $U_{S E}$ and $\tau_{r}$ to minimize the least squared error using curve fit from scipy.optimize. If the $\mathrm{R}^{2}$ for the linear regression between each train and the predicted values from the best fit was greater than 0.8 , the trace was used in the calculation of the mean of the parameter values. Smaller values indicated a noisy trace, likely from a small synapse. Maximum likelihood estimation of the parameters yielded similar values and the data sets passed a Shapiro-Wilcox test for normality. The Akaike Information Criterion and RMS yielded similar results to $\mathrm{R}^{2}$ but we chose to use $\mathrm{R}^{2}$ to accept or reject data sets because the values are constrained (between $\mathrm{o}$ and 1 ) whereas the other metrics are not. The expression above sufficed for the connections between interneurons (Sst-Sst and Pvalb-Pvalb). The fit to the data from synapses onto the excitatory cells were improved by adding a correction for temporal summation from up to three previous spikes $x_{k-j} e^{-\frac{j}{f \tau_{r}}}$ where $\mathrm{j}$ is the index of whether the contribution is from the immediately preceding spike $(j=1)$ or father back in the spike train The previously measured time constant for synaptic decay at each synapse was used rather than fitting an additional unknown parameter.

\section{Results}

\section{High degree of connectivity between mEC Pvalb+ interneurons}

To address the likelihood of connections and synaptic kinetics of inhibition from layer $2 / 3$ parvalbumin $\left(\mathrm{Pvalb}^{+}\right)$- and somatostatin $\left(\mathrm{Sst}^{+}\right)$-positive interneurons, we performed dual intracellular patch recordings in mice expressing the tdTomato fluorophore in Pvalb ${ }^{+}$or Sst+ cells. We targeted both fluorescent and non-fluorescent cells and used intracellular electrophysiological measures to distinguish between subtypes of non-fluorescent cells (pyramidal and stellate cells) in layer 2. 
Aside from the fluorescent marker, Pvalb ${ }^{+}$cells could be differentiated from excitatory cells due a much smaller membrane time constant (6.8 ms [Q1 3.72 Q3 8.0]; $\mathrm{p}<0.001$, KruskalWallis ANOVA; Fig. 1Aii) and spike half-width (o.29 ms [Q1 0.27 Q3 0.32], $\mathrm{p}<0.001$; KruskalWallis ANOVA; Fig. 1Aiii), which is consistent with the fast-firing phenotype. In addition, we distinguished between layer 2 pyramidal and stellate cells using the membrane overshoot in response to a negative current pulse associated with the expression of a hyperpolarizingactivated cation current $\left(\mathrm{I}_{\mathrm{H}}\right)$ and the membrane decay time constant; stellate cells expressed significantly larger membrane overshoots in response to a hyperpolarizing current $(3.43 \pm 2.13$ $\mathrm{mV}$ vs. $0.45 \pm 0.44 \mathrm{mV}, \mathrm{p}<0.001$, two-way student t-test; Fig. 1Aiv). Combined with a smaller membrane time constant, the two factors could be used to differentiate most stellate cells from pyramidal cells (Fig. 1Aiv). In cases where neither of these two factors was applicable, we used the presence of peri-threshold oscillations to distinguish cells (only used in 5 cells). To detect synapses and gap junctions, we averaged between 25 and 50 sweeps in voltage clamp (held at $40 \mathrm{mV}$ ) while driving a spike using a brief current pulse (2 ms) in the other neuron.

At pair distances between $\mathrm{O}$ and $150 \mu \mathrm{m}$, we observed a high probability of connection between mEC Pvalb+ interneurons. Over all distances tested, we found that 76/122 pairs expressed a connection either in the form of a chemical synapse (43/122), a gap junction (6/122) or both (27/122) (Fig. 1Bi); therefore, the probability of chemical synaptic connectivity was 35.7 $\%(87 / 244)$ in each direction and the probability of bidirectional gap junctional connectivity was $27 \%$ (33/122). At distances greater than $150 \mu \mathrm{m}$, connection probability (of either type) fell sharply (Fig 1Biii), which is consistent with the extent of axonal arborization of Pvalb $^{+}$ interneurons within layer 2/3 (Martínez et al., 2017; Grosser et al., 2021). We also found that the synaptic amplitude for uni-directionally connected pairs (21.4 pA [Q1 12.9 Q3 41.o]) did not differ significantly from the size of synapses present in bi-directionally connected pairs (30.9 pA [Q1 17.8 Q3 60.7], $\mathrm{p}=$ 0.12; Mann-Whitney test; Fig.1Biv). Using a step depolarization between 10 and $20 \mathrm{mV}$ in one cell, we measured the strength of gap junction connections between Pvalb ${ }^{+}$ cells as the ratio of the two voltage responses. This value was 0.03 [Q1 0.02 Q3 0.06$]$ across 17 measured pairs.

Next, the prevalence of gap junctions was measured between synaptically connected and unconnected pairs. In our data set, synaptically unconnected pairs occurred at longer pair distances than those of unidirectional or bidirectional connections (Fig. 1Bii). To eliminate this feature from artificially lowering the prevalence of gap junctions in synaptically unconnected pairs, we limited our analysis to pairs at distances between 20 and $125 \mu \mathrm{m}$. Under this constraint, the pair distances for all 3 categories of synaptic connections were statistically similar ( $\mathrm{p}=0.57$; one-way ANOVA; no connection: $76.4 \pm 23.9 \mu \mathrm{m}$; unidirectional: $75.4 \pm 26.8$ $\mu \mathrm{m}$; bidirectional: $68.9 \pm 27.3 \mu \mathrm{m}$; Fig. $1 \mathrm{Bv}$, inset). Using this data set, we found that the probability of gap junctions was significantly greater in bi-directionally ( $0.53 \mathrm{vs}$. $0.17, \mathrm{p}=0.01$; two-sided Fisher test), but not uni-directionally, connected pairs when compared to unconnected pairs (Fig. 1Bv).

\section{Connectivity and kinetics between mEC Pvalb+ interneurons and excitatory neurons}

We carried out a similar set of analyses for connections between Pvalb ${ }^{+}$and excitatory cells ( $\mathrm{I}_{\text {Pvalb }}-\mathrm{E}$; Fig. 2A). Unlike interneuron pairs, we never observed gap junctions in $\mathrm{I}_{\text {Pvalb }}-\mathrm{E}$ cell pairs. Connection likelihood was also generally lower for $\mathrm{I}_{\mathrm{pvalb}} \mathrm{E}$ pairs compared to $\mathrm{I}_{\mathrm{pvalb}}-\mathrm{I}_{\mathrm{P} \text { valb }}$ pairs. Including both excitatory cell types, 38 of 85 Ipvalb $-\mathrm{E}$ pairs were connected in comparison to 76 of $122 \mathrm{I}_{\text {Pvalb }}-\mathrm{I}_{\text {Pvalb }}$ pairs ( $\mathrm{p}=0.02$; two-sided Fisher test). There were 26 unidirectional connections and 12 bidirectional connections; therefore, the probability of chemical synaptic connectivity was $29.4 \%(50 / 170)$ in each direction. Both pyramidal and stellate cells expressed statistically similar ratios of unconnected and connected pairs $(33 / 26$ vs. $14 / 12,=0.99$; twosided Fisher test; Fig. $2 \mathrm{Bi}, \mathrm{Ci}$ ) For both cell types, connection probability also dropped off at 
distances greater than $100 \mu \mathrm{m}$ (Fig. 2Biii, Ciii). Like $\mathrm{I}_{\text {Pvalb }}-\mathrm{I}_{\text {Pvalb }}$ pairs, we found no significant difference in the size of inhibitory synapses between uni-directionally and bi-directionally connected pairs of Pvalb ${ }^{+}$and pyramidal ( $\mathrm{I}_{\mathrm{Pvalb}}-\mathrm{E}_{\mathrm{Pyr}}$ ) cells (31.1 pA [Q1 18.4 Q3 100.2] vs. 14.2 pA [Q1 7.6 Q3 94.4], $\mathrm{p}=0.23$; Mann-Whitney test; Fig. 2Biv); we did not have enough bidirectionally connected $\mathrm{Pvalb}^{+}$-stellate $\left(\mathrm{I}_{\text {Pvalb }}-\mathrm{E}_{\text {Stel }}\right)$ cell pairs to test potential differences in this measure (Fig. 2Civ).

The kinetics of inhibition indicated clear differences among the 3 cell types. We focused on amplitude, decay time, delay and rise time as these properties are crucial in many models of inhibitory activity with regards to synchrony and oscillations (Bartos et al., 2007; Economo and White, 2012; Keeley et al., 2017). The largest difference amongst these parameters was the inhibitory decay time constant (single exponential fit; Kruskal-Wallis ANOVA, $\mathrm{p}<0.001$; Fig. 3Aii). Synaptic inhibition decayed much faster in $\mathrm{Pvalb}^{+}$cells than in either pyramidal or stellate cells (2.0 ms [Q1 1.7 Q3 2.6] vs. 5.5 ms [Q1 4.9 Q3 6.6] and $12.1 \mathrm{~ms}$ [Q1 6.0 Q3 14.5], p < 0.001; Dunn's test; Fig. 3Aii). Although generally larger, the difference in decay time constants between stellate and pyramidal cells did not reach the significance threshold ( $\mathrm{p}=0.75$; Dunn's test, Fig. 3Aii).

We also found differences in the rise time constant between $I_{\text {Pvalb }}-I_{P v a l b}$ and stellate cell pairs ( $\mathrm{p}=0.002$; Kruskal-Wallis ANOVA), with stellate cells showing larger rise time constants (0.34 ms [Q1 0.28 Q3 0.44 ] vs. $0.58 \mathrm{~ms}$ [Q1 0.40 Q3 0.81], p = 0.002; Fig. 3Aiii). In contrast, neither delay time $(\mathrm{p}=0.12$; one-way ANOVA) nor peak amplitude $(\mathrm{p}=0.06$; Kruskal-Wallis ANOVA) differed amongst the 3 pair categories (Fig. 3Ai, iv). Consistent with previous measures of excitatory (Song et al., 2005) and inhibitory (Bartos et al., 2001) synapses in other regions, the amplitude of inhibitory synapses expressed strong, non-Gaussian distributions (ShapiroWilk and Lilliefors test, $\mathrm{p}<0.001)$. Distributions of $\mathrm{I}_{\text {pvalb }}-\mathrm{I}_{\mathrm{Pvalb}}$ and $\mathrm{I}_{\mathrm{Pvalb}}-\mathrm{E}$ cell pair synaptic amplitudes fit an exponential decay and were dominated by small synapses accompanied by fewer, larger synapses (Fig. 3Bi, ii).

\section{Connectivity and kinetics between $\mathrm{mEC} \mathrm{Sst^{+ }}$ interneurons}

Next, we focused on inhibition from $\mathrm{Sst}^{+}$interneurons. As with $\mathrm{Pvalb}^{+}$neurons, $\mathrm{Sst}^{+}$neurons could be differentiated from pyramidal cells through their membrane decay time constant and spike half-width (Fig. 4A). Although not as small as Pvalb ${ }^{+}$neurons, both membrane time constant (13.1 ms [Q1 7.9 Q3 25.3] vs $39.2 \mathrm{~ms}$ [Q1 29.0 Q3 51.0]) and spike half-width (o.57 ms $\left[\begin{array}{lllll}Q 1 & 0.41 & Q 3 & 0.68\end{array}\right]$ vs $\left.1.0 \mathrm{~ms}\left[\begin{array}{lll}0.98 & 03 & 1.2\end{array}\right]\right)$ were significantly smaller than those of pyramidal cells ( $<$ 0.001; Dunn's test, Fig. 4Aii).

Over all distances tested, we found that $16 / 59 \mathrm{Sst}^{+}$pairs expressed a connection either in the form of a chemical synapse (14/59) or a gap junction (2/59) (Fig. 4Bi). Compared with $\mathrm{I}_{\mathrm{Pvalb}^{-}}$ $\mathrm{I}_{\text {pvalb }}$ pairs, synaptic and gap connections between $\mathrm{I}_{\mathrm{Sst}}-\mathrm{I}_{\mathrm{Sst}}$ neurons were far less likely $(\mathrm{p}<0.001$, Fisher test). Crucially, due to the lack of connections at distances greater than $100 \mu \mathrm{m}$ (Fig. 4iv), our average $\mathrm{I}_{\text {Sst }}-\mathrm{I}_{\text {sst }}$ pair distance was shorter than $\mathrm{I}_{\text {Pvalb }}-\mathrm{I}_{\text {Pvalb }}$ pairs $(46.7 \mu \mathrm{m}[Q 128.9$ Q3 65.0] vs $81.3 \mu \mathrm{m}[Q 161.9$ Q3 116]). Thus, despite shorter pair distances, connections probabilities were still far lower than those of $\mathrm{I}_{\text {Pvalb }} \mathrm{I}_{\text {Pvalb }}$ pairs. We also found that the amplitude of synapses between $\mathrm{I}_{\mathrm{Sst}}-\mathrm{I}_{\mathrm{Sst}}$ pairs was significantly different depending on whether cells were unidirectionally or bidirectionally connected (6.0 pA [ [ $\left.\begin{array}{llll}Q_{1} & 5.2 & Q 3 & 8.1\end{array}\right]$ vs. $15.1 \mathrm{pA}\left[\begin{array}{lll}Q_{1} & 8.6 & Q_{3}\end{array}\right.$ 26.4], $\mathrm{p}=0.02$; Mann-Whitney test; Fig. 4Biii). Unlike $\mathrm{I}_{\text {Pvalb }}-\mathrm{I}_{\text {Pvalb }}$ pairs, gap junctions in $\mathrm{I}_{\text {Sst }} \mathrm{I}_{\text {Sst }}$ pairs were observed in only two pairs, both of which also had bidirectional synaptic connections.

\section{Connectivity and kinetics between $\mathrm{mEC} S \mathrm{St}^{+}$interneurons and pyramidal cells}

For $\mathrm{I}_{\text {Sst }} \mathrm{E}$ pairs, we limited our measures to pyramidal cells as we only observed 3 pairs containing stellate cells, with only 1 of these pairs being connected. This is likely due to the 
deeper location of $\mathrm{Sst}^{+}$neurons within layer 2/3 (Tremblay et al., 2016), as well as lower overall density across cortical layers (Amitai et al., 2002). This is also consistent with optogenetic experiments indicating greater connectivity between $\mathrm{Sst}^{+}$and pyramidal cells (Kecskés et al., 2020). In contrast to $I_{S s t}-I_{s s t}$ pairs, connection probabilities between $I_{\text {sst }}-E_{\text {Pyr }}$ were not significantly lower than those measured in $\mathrm{I}_{\text {pvalb }}$-E pairs (12/41 vs. 38/85, $\mathrm{p}=0.12$; two-sided Fisher test). If, however, we limited our connection measures in $\mathrm{I}_{\text {Pvalb }}-\mathrm{E}$ pairs to a range similar those of Isst- Eyr $_{\text {Pyirs }}$ pai $\left.-125 \mu \mathrm{m}\right)$, connection probability was indeed lower (12/41 vs. 37/73, $\mathrm{p}=0.03$; two-sided Fisher test). The amplitude of synapses between $\mathrm{I}_{\mathrm{Sst}} \mathrm{E}_{\mathrm{Pyr}}$ pairs also seemed to depend on whether cells were unidirectionally or bidirectionally connected. The difference, however, was at the margin of statistical significance (10.7 pA [Q1 3.7 Q3 20.9] vs. 39.4 pA [Q1 23.5 Q3 81.0], p = 0.05; Mann-Whitney test; Fig. 4Ciii).

As with Pvalb ${ }^{+}$cells, inhibition from $\mathrm{Sst}^{+}$cells onto pyramidal cells was significantly slower to decay than that between $\mathrm{Sst}^{+}$cells (2.8 ms [Q1 2.2 Q3 5.2] vs $10.3 \mathrm{~ms}$ [Q1 6.9 Q3 14.9], $\mathrm{p}<$ 0.001; Mann-Whitney test; Fig. 5Aii). We also noted significantly longer delays in pyramidal cells $(1.1 \pm 0.14$ ms vs. $1.4 \pm 0.08, p=0.04$; Student $t$-test $)$. Both peak amplitude and rise time constants, however, were not significantly different $(\mathrm{p}=0.18$ and $\mathrm{p}=0.89$; Mann-Whitney test; Fig. 5Ai, Aiii). Again, distributions of peak inhibitory amplitude in both $\mathrm{SSt}^{+}$and pyramidal cells expressed non-Gaussian distributions ( $\mathrm{p}<\mathrm{0.001}$; Shapiro-Wilk and Lilliefors test) and could be fit with exponential functions (Fig. $5 \mathrm{Bi}$, Bii).

\section{$\mathrm{Pvalb}^{+}$and $\mathrm{Sst}^{+}$interneuron-based inhibition express different decay and delay times}

Comparison of inhibition in $\mathrm{I}_{\text {Sst }}-\mathrm{I}_{\mathrm{Sst}}$ and $\mathrm{I}_{\mathrm{Pvalb}}-\mathrm{I}_{\mathrm{Pvalb}}$ pairs also indicated numerous differences. Inhibitory peak amplitude in $\mathrm{I}_{\text {Sst }}-\mathrm{I}_{\text {Sst }}$ pairs was significantly smaller $(\mathrm{p}=0.002$; Mann-Whitney test), with larger decay time constants ( $\mathrm{p}<0.001$; Mann-Whitney test) and longer delays $(\mathrm{p}=$ 0.003; Mann-Whitney test) than those measured in $\mathrm{I}_{\text {Pvalb }}-\mathrm{I}_{\text {Pvalb }}$ pairs (Fig. 6Ai-iv). Similarly, we also noted differences between $\mathrm{I}_{\mathrm{Sst}}-\mathrm{E}_{\mathrm{Pyr}}$ and $\mathrm{I}_{\mathrm{P} v a l b}-\mathrm{E}_{\mathrm{Pyr}}$ pairs. These included larger decay time constants ( $p=0.005$; Mann-Whitney test; Fig. 6Bii) and delay times ( $p=0.002$; Mann-Whitney test; Fig. 6Biii) in $\mathrm{I}_{\mathrm{Sst}}-\mathrm{E}_{\mathrm{Pyr}}$ pairs.

\section{I-I synapses express greater synaptic depression than I-E synapses}

Using $200 \mathrm{~ms}$-long pulse trains between $5-200 \mathrm{~Hz}$, we proceeded to measure the degree of synaptic depression at different stimulus frequencies. In both $\mathrm{I}_{\text {Pvalb }}-\mathrm{I}_{\text {pvalb }}$ and $\mathrm{I}_{\text {Pvalb }}-\mathrm{E}$ synapses, depression was often observed at frequencies as low as $5-10 \mathrm{~Hz}$ (Fig 7A-C). In all 3 cell types, synaptic depression increased as a function of stimulus frequency (Fig. 7Di). To compare differences in the depression, we measured the depression decay time constant and steady-state value at $50 \mathrm{~Hz}$, a frequency in which depression was observed reliably in all 3 cells and which reached a steady-state value within our stimulus time frame. As shown, the depression decay time constant and the steady-state value indicated faster and greater depression in $\mathrm{I}_{\text {Pvalb }}-\mathrm{I}_{\text {Pvalb }}$ synapses than in either type of $\mathrm{I}_{\text {Pvalb }}-\mathrm{E}$ connection $(\mathrm{n}=61,20,12, \mathrm{p}<0.001$, one-way ANOVA; Fig. 7Dii, iii), with $\mathrm{I}_{\text {Pvalb }}-I_{\text {Pvalb }}$ pairs expressing a time constant of $20.6 \pm 7.2 \mathrm{~ms}$ (versus $34.9 \pm$ $11.7 \mathrm{~ms}$ and $40.5 \pm 13.6 \mathrm{~ms}, \mathrm{p}=0.004$; Bonferroni test; Fig. 7 Dii) and a steady-state value at 50 $\mathrm{Hz}$ of $0.44 \pm 0.11$ (vs. $0.55 \pm 0.11$ and $0.68 \pm 0.11, \mathrm{p}=0.01$ and $\mathrm{p}<0.001$; Bonferroni test; Fig. 7Diii).

Using an identical stimulus range, we also measured the depression at $\mathrm{I}_{\text {sst }}-\mathrm{I}_{\mathrm{sst}}$ and $\mathrm{I}_{\text {sst }}$ E $_{\text {Prr }}$ synapses. Again, synaptic depression was observed at frequencies as low as $5-10 \mathrm{~Hz}$. Like Pvalb ${ }^{+}$cells, $\mathrm{I}_{\mathrm{sst}}-\mathrm{I}_{\mathrm{sst}}$ synapses depressed more quickly and to a greater extent than $\mathrm{I}_{\mathrm{sst}}-\mathrm{E}_{\mathrm{Pyr}}$ synapses (Fig. 8A-C). The depression decay time constant in response to $50 \mathrm{~Hz}$ stimulus trains for $\mathrm{I}_{\text {Sst }}-\mathrm{I}_{\text {Sst }}$ pairs was $20.1 \mathrm{~ms}$ [Q1 15.7 Q3 26.9], which was significantly smaller than the $51.9 \mathrm{~ms}$ [Q1 38.8 Q3 76.9] measured in $\mathrm{I}_{\mathrm{Sst}}-\mathrm{E}_{\mathrm{Pyr}}$ synapses $(\mathrm{n}=2 \mathrm{O}, 13, \mathrm{p}=0.002$; Mann-Whitney test; Fig. 
8Ci). Steady-state levels at $50 \mathrm{~Hz}$ also differed, with $\mathrm{I}_{\mathrm{Sst}}-\mathrm{I}_{\mathrm{Sst}}$ pairs depressing to 0.44 [Q1 0.42 Q3 o.62] compared with 0.65 [Q1 0.55 Q3 0.74 in $\mathrm{I}_{\mathrm{Sst}}-\mathrm{E}_{\mathrm{Pyr}}(\mathrm{p}=0.007$; Mann-Whitney test; Fig. 8 Ciii). Finally, there was no difference in the synaptic depression time constants $(\mathrm{p}=0.55$; Mann-Whitney test) and steady-state levels $(\mathrm{p}=0.55$; Mann-Whitney test) of synaptic depression in response to $50 \mathrm{~Hz}$ between $\mathrm{I}_{\text {pvalb }}-\mathrm{I}_{\mathrm{Pvalb}}$ and $\mathrm{I}_{\mathrm{Sst}}-\mathrm{I}_{\mathrm{Sst}}$ pairs.

\section{Modeling synaptic kinetics and short depression}

To examine whether our results could be framed using previous mechanism of synaptic depression, we used a model of short-term depression developed by Markram and Tsodyks (1996) to fit our measures of post-synaptic current decay and depression (Markram and Tsodyks, 1996; Stimberg et al., 2019). In Figure 9, we show the best fitting models of synaptic depression as described in the Methods section. Because the synaptic decay time constants were much smaller for synapses between interneurons (Fig. 9A and D; $\mathrm{I}_{\text {Pvalb }}-\mathrm{I}_{\text {Pvalb }}$ and $\mathrm{I}_{\text {Sst }}-\mathrm{I}_{\text {sst }}$, respectively) we were able to ignore temporal summation between successive post synaptic currents and still obtain a good fit. In contrast, synapses onto excitatory cells were generally slow enough that including their previously measured synaptic decay constants in the model as described in the Methods greatly improved the fit of the model (Fig. 9B, C and E for $\mathrm{I}_{\text {Pvalb }}-\mathrm{E}_{\mathrm{Pyr}}$, $\mathrm{I}_{\mathrm{Sst}}-\mathrm{E}_{\mathrm{Pyr}}$ and $\mathrm{I}_{\mathrm{Pvalb}}-\mathrm{E}_{\mathrm{Stel}}$, respectively). This is consistent with the observation that inhibitory currents decay more slowly on excitatory compared to inhibitory neurons (Ma et al., 2012). The summary panel in Figure $9 \mathrm{~F}$ shows that the time constants for recovery from depression ranges from about 50 to $150 \mathrm{~ms}$, with no systematic differences in their values, as confirmed by the statistics in Table 1 ( $\mathrm{p}=0.89$; one-way ANOVA). Most values of $U_{S E}$ fall in the range 0.2 to 0.5 , with some lower values (corresponding to less depression) associated with synapses onto pyramidal neurons (green and yellow symbols). Values, however, were not significantly different ( $\mathrm{p}>0.05$; Dunn's test).

\section{Discussion}

In summary, we find that inhibition in $\mathrm{I}_{\text {Pvalb }}-\mathrm{I}_{\mathrm{Pvalb}}$ and $\mathrm{I}_{\text {Pvalb }}-\mathrm{E}$ pairs in layer $2 / 3 \mathrm{mEC}$ are stronger, faster, and more interconnected, both in term of synapses and gap junctions, than those measured in $\mathrm{I}_{\mathrm{Sst}}-\mathrm{I}_{\mathrm{Sst}}$ and $\mathrm{I}_{\mathrm{Sst}}-\mathrm{E}_{\mathrm{Pyr}}$ pairs. Further, for both $\mathrm{Pvalb}^{+}$and $\mathrm{Sst}^{+}$cells, inhibitory synaptic currents between interneuron pairs were faster to decay than in the excitatory cells; the inhibitory current decay time constant and delay time, however, were smaller and shorter, respectively, in $\mathrm{Pvalb}^{+}$cells. Although we noted some minor differences, Pvalb ${ }^{+}$inhibition onto pyramidal and stellate cells was generally similar. In contrast to previous measures in visual cortex (Pfeffer et al., 2013), we found significant evidence for inhibitory connections between $\mathrm{Sst}^{+}$interneurons. Finally, inhibition between interneurons expressed faster and greater synaptic depression than those onto excitatory cells.

\section{Comparison with past measures of inhibitory synaptic currents}

Like measures in neocortex (Beierlein et al., 2003) and hippocampus (Bartos et al., 2002), $\mathrm{I}_{\text {Pvalb- }}$ $\mathrm{I}_{\mathrm{p} \text { valb }}$ pairs expressed fast decaying synapses that were strongly depressing. These cell pairs also contained a high prevalence of gap junction connections, albeit with a lower likelihood than those measured in other neocortical regions (Gibson et al., 1999; Hjorth et al., 2009). Similarly, we also noted gap junction connections in $\mathrm{I}_{\mathrm{Sst}}-\mathrm{I}_{\mathrm{Sst}}$ pairs, but these were far less frequent than in $\mathrm{I}_{\text {Pvalb }}-\mathrm{I}_{\text {Pvalb }}$ pairs. This contrasts with measures in neocortex in which $\mathrm{I}_{\text {sst }}-\mathrm{I}_{\text {sst }}$ pairs are highly interconnected through gap junctions ( $>65 \%$ of pairs)(Amitai et al., 2002; Fanselow et al., 2008). Also, in contrast to neocortex (Pfeffer et al., 2013), we measured substantial synaptic connections between $\mathrm{Sst}^{+}$neurons. These stark difference might arise, in part, from the large 
diversity within the $\mathrm{Sst}^{+}$population, which likely includes at least 4 different subtypes of interneurons across different cortical regions and layers (Urban-Ciecko and Barth, 2016; Yavorska and Wehr, 2016). Our analysis of spike half-width shows that SST+ cells share a similar range of variance as those in measured Pvalb ${ }^{+}$cells. This suggests a narrowly defined population in layer $2 / 3$ of the mEC.

Similar to CA1 (Bartos et al., 2002), we found that the inhibition decay time constants from Pvalb $^{+}$is target cell specific, with smaller decay time constants in Pvalb ${ }^{+}$cells; this was also true for $\mathrm{Sst}^{+}$interneurons. A key factor in determining the kinetics of $\mathrm{GABA}_{\mathrm{A}}$ receptor-mediated inhibition is the subunit composition of the receptor (Fritschy and Brünig, 2003; Barberis et al., 2007). Faster decay times are associated with the presence of the alpha-1 and alpha-2 subunits (Barberis et al., 2007). Immunohistochemical work in layer $2 \mathrm{mEC}$ indicates a greater prevalence of the alpha-1 subunit in $\mathrm{Pvalb}^{+}$cells than in either reelin (stellate)- or calbindin (pyramidal)-positive excitatory cells (Berggaard et al., 2018). As a result, the faster decay time of inhibition can be explained by different subunit compositions that support a faster inactivation of the receptor in Pvalb ${ }^{+}$cells.

\section{Interneuron role in synchrony and gamma oscillations}

Fast-firing interneurons are generally assumed to underlie fast negative feedback that is critical to balancing network excitation and inhibition (Wehr and Zador, 2003; Okun and Lampl, 2008; Atallah and Scanziani, 2009; Isaacson and Scanziani, 2011). In addition, for cells in close proximity $(<100 \mu \mathrm{m})$, nearly half of fast-firing interneurons are connected through gap junctions (Deans et al., 2001). These features support network synchrony, as well as the generation of fast gamma frequency oscillations (Beierlein et al., 2000; Deans et al., 2001; Bartos et al., 2002; Mann and Paulsen, 2007; Atallah and Scanziani, 2009; Pastoll et al., 2013). Consistent with this function, we observed that Pvalb ${ }^{+}$cells inhibition onto pyramidal cells was faster to decay and arrived with a smaller delay time than $\mathrm{Sst}^{+}$cells. Pvalb ${ }^{+}$cells also expressed a higher prevalence of gap junction connections, and a much higher degree of interconnectivity between Pvalb+ neurons.

In models, the unique kinetics and connectivity properties of fast-firing interneurons can also generate gamma oscillations using solely an inhibitory network (Bartos et al., 2002, 2007; Tiesinga and Sejnowski, 2009; Tikidji-Hamburyan et al., 2015; Keeley et al., 2017; TikidjiHamburyan and Canavier, 2020), with experimental support for this form oscillatory activity noted in the hippocampus and entorhinal cortex (Butler et al., 2016, 2018). In contrast, neocortical $\mathrm{Sst}^{+}$interneurons in vivo do not correlate with oscillatory network activity (Kwan and Dan, 2012). Although differences in inputs are likely involved (Pfeffer et al., 2013; Yavorska and Wehr, 2016), the lower synaptic and gap junction connectivity that we observed may also contribute to lower synchrony levels.

Like $\mathrm{Pvalb}^{+}$cells, inhibition in $\mathrm{Sst}^{+}$cells was faster to decay than that in excitatory neurons. The faster decay times of inhibition between interneurons, therefore, may serve roles independent of network synchrony and oscillations. For example, a longer inhibitory decay time onto excitatory targets may arise as a compensation mechanism for the larger membrane time constants of these cells relative to both $\mathrm{Pvalb}^{+}$and $\mathrm{Sst}^{+}$interneurons. The average firing rates of excitatory cells in layer $2 \mathrm{mEC}$ are also typically lower than those in inhibitory cells (Frank et al., 2001), such that a proportional impact on spike rate requires longer lasting inhibition. As a result, differences in the inhibition kinetics may serve to compensate for differences in the neurophysiology of the post-synaptic target.

\section{Kinetics of inhibition in pyramidal and stellate cells}


Inhibition originating from $\mathrm{Pvalb}^{+}$cell was generally very similar in pyramidal and stellate cells. The only small and significant difference was the greater degree of steady-state depression in pyramidal cells when synapses were driven at $50 \mathrm{~Hz}$. This would appear to be consistent with the central role of Pvalb ${ }^{+}$interneurons in shaping spatial selectivity of grid cells (Miao et al., 2017), which include both pyramidal and stellate cells (Domnisoru et al., 2013; Tang et al., 2014). Our results are also consistent with a recent comparison of Pvalb+ inhibition onto stellate and pyramidal cells along the dorsal-ventral axis (Grosser et al., 2021). The authors reported no difference in the amplitude, paired-pulse ratio, and connectivity likelihood between inhibition in stellate and pyramidal cells (Grosser et al., 2021). Nevertheless, past work has indicated stronger labeling for the slower alpha-3 $\mathrm{GABA}_{\mathrm{A}}$ receptor subunit in stellate cells (Berggaard et al., 2018). Although we noted a tendency for inhibition to be slower in stellate cells, this difference did not reach significance.

\section{Synaptic depression in fast firing interneurons}

Parvalbumin is a $\mathrm{Ca}^{2+}$ buffer with slow kinetics that has been shown to mediate paired-pulse depression (Caillard et al., 2000). Although synapses between fast-firing neurons have not been as well studied as inhibition in excitatory cells, synapses between fast firing neurons in hippocampal area $\mathrm{CA} 3$ (Kohus et al., 2016) and the dentate gyrus both exhibit short-term depression (Bartos et al., 2001). Similarly, synapses from Pvalb+ neurons in the medial septum diagonal band of Broca (MS-DBB) onto CA1 stratum oriens interneurons and from local hippocampal Pvalb+ interneurons onto CA1 pyramidal neurons both exhibit short-term depression (Yi et al., 2021). Previously, different subtypes of Pvalb ${ }^{+} \mathrm{CA1}$ pyramidal neurons were found to have different paired pulse ratios (Maccaferri et al., 2000) in synapses onto principal cells, with the axo-axonic cell exhibiting more paired-pulse depression (PPD) than in basket cells and bistratified cells. In area $\mathrm{CA}_{3}$, the synapses of axo-axonic cells and Pvalb ${ }^{+}$basket cells onto the principal cells both exhibit short term depression; carbachol decreases the inhibitory synaptic current magnitude but eliminates or greatly reduces short-term depression (Szabó et al., 2010). Pvalb ${ }^{+}$, basket cells synapses onto their principal cell targets in the dentate gyrus also exhibit paired pulse depression (Kraushaar and Jonas, 2000). In the striatum, the synapses of fast spiking interneurons onto medium spiny striatal neurons also exhibit short-term depression (Gittis et al., 2010). Synapses from fast firing interneurons onto pyramidal cells in neocortex also exhibit short-term depression, albeit not as much as synapses between pyramidal cells (Galarreta and Hestrin, 1998). This study extends the evidence for short term depression as a characteristic feature of Pvalb ${ }^{+}$interneurons. However, the short-term depression observed here for $\mathrm{Sst}^{+}$interneurons may not be as general; for example, in mouse layer 4 somatosensory cortex, synapses made by $\mathrm{Sst}^{+}$cells depressed much less than those made by $\mathrm{Pvalb}^{+}$cells, and have a late component of facilitation (Ma et al., 2012). Short term synaptic plasticity may be an important mechanism that allows neurons to detect complex temporal structures by functioning as a memory of events in the past few hundred milliseconds (Motanis et al., 2018).

\section{Figure 1}

Synaptic and gap junction connections between Pvalb ${ }^{+}$interneurons. A, Example traces from Pvalb $^{+}$cells in response to current steps, along with examples of gap junction and synaptic connections (i). Membrane time constant (ii) and spike half-width (iii) measures in $\mathrm{Pvalb}^{+}$, 
pyramidal and stellate cells, along with a plot of membrane voltage sag and time constant in pyramidal and stellate cells (iv). B, Distribution and probability of connection types between $\mathrm{Pvalb}^{+}$interneurons. Pie chart indicating the distribution of connection types between $\mathrm{Pvalb}^{+}$ interneurons. Plots of pair distance as a function of synaptic connection type (none, one-way, two-way; ii) and connection probability of pairs between 20 and $250 \mu \mathrm{m}$ (iii). Peak inhibitory synaptic amplitude in one-way and two-way connected Pvalb ${ }^{+}$interneurons (iv). Plot of gap junction probability in unconnected, one-, and two-way connected Pvalb ${ }^{+}$interneuron pairs at distance between 20 and $125 \mu \mathrm{m}$.

\section{Figure 2}

Synaptic connections between Pvalb ${ }^{+}$interneurons and excitatory cells. $\boldsymbol{A}$, Distribution of connections between Pvalb $^{+}$and pyramidal cells. Pie chart indicating the distribution of connection types between Pvalb ${ }^{+}$and pyramidal cells. Plots of pair distance as a function of synaptic connection type (none, one-way, two-way; ii) and connection probability between 20 and $250 \mu \mathrm{m}$ (iii). Peak inhibitory synaptic amplitude in one-way and two-way connected Pvalb ${ }^{+}$ interneurons (iv). B, Distribution of connections between Pvalb ${ }^{+}$and pyramidal cells. Pie chart indicating the distribution of connection types between Pvalb $^{+}$and stellate cells. Plots of pair distance as a function of synaptic connection type (none, one-way, two-way; ii) and connection probability between 20 and $250 \mu \mathrm{m}$ (iii). Peak inhibitory synaptic amplitude in one-way and two-way connected Pvalb+ interneurons (iv).

\section{Figure 3}

Synaptic inhibitory properties from Pvalb+ interneurons. $\boldsymbol{A}$, Comparison of peak amplitude (i), inhibitory decay time constant (ii), inhibitory rise time constant (iii), and delay time (iv). $\boldsymbol{B}$, Distributions of inhibitory synaptic amplitude in Pvalb ${ }^{+}$interneurons and excitatory cells (stellate and pyramidal cells were pooled together). Histograms were fit with a single exponential function.

\section{Figure 4}

Synaptic and gap junction connections from Sst ${ }^{+}$interneurons. $\boldsymbol{A}$, Membrane time constant (i) and spike half-width (ii) measures in $\mathrm{Sst}^{+}$and pyramidal cells. $\boldsymbol{B}$, Distribution of connection types and probability between $\mathrm{Sst}^{+}$interneurons. Pie chart indicating the distribution of connection types between Sst ${ }^{+}$and pyramidal cells. Plots of pair distance as a function of synaptic connection type (none, one-way, two-way; ii) and connection probability between 20 and $150 \mu \mathrm{m}$ (iii). Peak inhibitory synaptic amplitude in one-way and two-way connected $\mathrm{Sst}^{+}$ interneurons (iv). $\boldsymbol{C}$, Distribution of connections between $\mathrm{Sst}^{+}$and pyramidal cells. Pie chart indicating the distribution of connection types between $\mathrm{Sst}^{+}$and pyramidal cells. Plots of pair distance as a function of synaptic connection type (none, one-way, two-way; ii) and connection probability between 20 and $150 \mu \mathrm{m}$ (iii). Peak inhibitory synaptic amplitude in one-way and two-way connected $\mathrm{Sst}^{+}$interneurons (iv).

\section{Figure 5}

Synaptic inhibitory properties from $\mathrm{Sst}^{+}$interneurons. $\boldsymbol{A}$, Comparison of peak amplitude (i), inhibitory decay time constant (ii), inhibitory rise time constant (iii), and delay time (iv). $\boldsymbol{B}$, 
Distributions of inhibitory synaptic amplitude in $\mathrm{Sst}^{+}$interneurons and pyramidal cells. Histograms were fit with a single exponential function.

\section{Figure 6}

Synaptic inhibitory properties in interneurons $(\boldsymbol{A})$ and excitatory cells $(\boldsymbol{B}), \boldsymbol{A}, \boldsymbol{B}$, Comparison of peak amplitude (i), inhibitory decay time constant (ii), inhibitory rise time constant (iii), and delay time (iv) in synaptic connection in interneurons $(\boldsymbol{A})$ and excitatory cells $(\boldsymbol{B})$.

\section{Figure 7}

Synaptic inhibitory depression from $\mathrm{Pvalb}^{+}$cells in $\mathrm{Pvalb}^{+}$, pyramidal, and stellate cells. $\boldsymbol{A}-\boldsymbol{C}$, Measures of synaptic inhibitory depression in response to $200 \mathrm{~ms}$ pre-synaptic pulse trains between 5 and $200 \mathrm{~Hz}$ in Pvalb ${ }^{+}(\boldsymbol{A})$, pyramidal $(\boldsymbol{B})$, and stellate $(\boldsymbol{C})$ cells. For each cell, synaptic inhibitory amplitude was normalized by the peak amplitude of the first response during the train (ii). $\boldsymbol{D}$, Plot of average normalized synaptic inhibitory amplitude at the end of different pulse trains (i). Decay time constant associated with synaptic depression in response to $50 \mathrm{~Hz}$ pulse trains in $\mathrm{Pvalb}^{+}$, pyramidal, and stellate cells (ii). Relative steady-state value of peak inhibitory synaptic amplitude in response to $50 \mathrm{~Hz}$ pulse trains in $\mathrm{Pvalb}^{+}$, pyramidal, and stellate cells.

\section{Figure 8}

Synaptic inhibitory depression from $\mathrm{Sst}^{+}$cells in $\mathrm{Sst}^{+}$and pyramidal cells. $\boldsymbol{A}, \boldsymbol{B}$, Measures of synaptic inhibitory depression in response to $200 \mathrm{~ms}$ pre-synaptic pulse trains between 5 and $200 \mathrm{~Hz}$ in $\mathrm{Sst}^{+}(\boldsymbol{A})$ and pyramidal $(\boldsymbol{B})$. For each cell, synaptic inhibitory amplitude was normalized by the peak amplitude of the first response during the train (ii). $\boldsymbol{C}$, Plot of average normalized synaptic inhibitory amplitude at the end of different pulse trains (i). Decay time constant associated with synaptic depression in response to $50 \mathrm{~Hz}$ pulse trains in $\mathrm{Pvalb}^{+}$, pyramidal, and stellate cells (ii). Relative steady-state value of peak inhibitory synaptic amplitude in response to $50 \mathrm{~Hz}$ pulse trains in $\mathrm{Sst}^{+}$and pyramidal cells.

\section{Figure 9}

Modeling synaptic depression. The fits of inhibitory amplitude depression in response to $50 \mathrm{~Hz}$ trains of presynaptic stimulation are shown for selected examples for each synapse type. Data points are shown as filled circles. The values predicted by the best fit models are given by other shapes and colors. A, Pvalb-Pvalb only includes depression. B, Pvalb-Pyr includes both temporal summation and depression. $\boldsymbol{C}$, Sst-Pyr included both temporal summation and depression. D, Sst-Sst includes only depression. $\boldsymbol{E}$, Pvalb-Stel included both temporal summation and depression. This was the smallest data set and only the two traces shown had a good enough fit according to the criterion given in the Methods. F, Parameter summary. Parameter values are coded by synapse type: Pvalb-Pvalb (blue squares), Pvalb-Pyr (red triangles), Sst-Pyr (upside down orange triangles), SST-SST (green plus signs) and PV-STL (purple X's). Left. Time constant for recovery from synaptic depression. Right. Fraction of available transmitter released by each presynaptic spike.

\section{References}


Amitai Y, Gibson JR, Beierlein M, Patrick SL, Ho AM, Connors BW, Golomb D (2002) The Spatial Dimensions of Electrically Coupled Networks of Interneurons in the Neocortex. J Neurosci 22:4142-4152.

Atallah BV, Scanziani M (2009) Instantaneous modulation of gamma oscillation frequency by balancing excitation with inhibition. Neuron 62:566-577.

Barberis A, Mozrzymas JW, Ortinski PI, Vicini S (2007) Desensitization and binding properties determine distinct $\alpha_{1} \beta_{2} \gamma_{2}$ and $\alpha_{3} \beta_{2} \gamma_{2}$ GABAA receptor-channel kinetic behavior. European Journal of Neuroscience 25:2726-2740.

Bartos M, Vida I, Frotscher M, Geiger JRP, Jonas P (2001) Rapid Signaling at Inhibitory Synapses in a Dentate Gyrus Interneuron Network. J Neurosci 21:2687-2698.

Bartos M, Vida I, Frotscher M, Meyer A, Monyer H, Geiger JRP, Jonas P (2002) Fast synaptic inhibition promotes synchronized gamma oscillations in hippocampal interneuron networks. PNAS 99:13222-13227.

Bartos M, Vida I, Jonas P (2007) Synaptic mechanisms of synchronized gamma oscillations in inhibitory interneuron networks. Nat Rev Neurosci 8:45-56.

Beierlein M, Gibson JR, Connors BW (2000) A network of electrically coupled interneurons drives synchronized inhibition in neocortex. Nat Neurosci 3:904-910.

Beierlein M, Gibson JR, Connors BW (2003) Two Dynamically Distinct Inhibitory Networks in Layer 4 of the Neocortex. Journal of Neurophysiology 90:2987-3000.

Berggaard N, Seifi M, van der Want JJL, Swinny JD (2018) Spatiotemporal Distribution of GABAA Receptor Subunits Within Layer II of Mouse Medial Entorhinal Cortex: Implications for Grid Cell Excitability. Front Neuroanat o Available at: https://www.frontiersin.org/articles/10.3389/fnana.2018.00046/full.

Burgalossi A, Brecht M (2014) Cellular, columnar and modular organization of spatial representations in medial entorhinal cortex. Current Opinion in Neurobiology 24:47-54.

Butler JL, Hay YA, Paulsen O (2018) Comparison of three gamma oscillations in the mouse entorhinal-hippocampal system. European Journal of Neuroscience 48:2795-2806.

Butler JL, Mendonça PRF, Robinson HPC, Paulsen O (2016) Intrinsic Cornu Ammonis Area 1 Theta-Nested Gamma Oscillations Induced by Optogenetic Theta Frequency Stimulation. J Neurosci 36:4155-4169.

Caillard O, Moreno H, Schwaller B, Llano I, Celio MR, Marty A (200o) Role of the calciumbinding protein parvalbumin in short-term synaptic plasticity. Proc Natl Acad Sci U S A 97:13372-13377.

Colgin LL, Denninger T, Fyhn M, Hafting T, Bonnevie T, Jensen O, Moser M-B, Moser EI (2009) Frequency of gamma oscillations routes flow of information in the hippocampus. Nature 462:353-357.

Couey JJ, Witoelar A, Zhang S-J, Zheng K, Ye J, Dunn B, Czajkowski R, Moser M-B, Moser EI, Roudi Y, Witter MP (2013) Recurrent inhibitory circuitry as a mechanism for grid formation. Nat Neurosci 16:318-324. 
de Filippo R, Rost BR, Stumpf A, Cooper C, Tukker JJ, Harms C, Beed P, Schmitz D (2021) Somatostatin interneurons activated by 5 -HT2A receptor suppress slow oscillations in medial entorhinal cortex Colgin LL, Vinck M, Fernandez-Ruiz A, eds. eLife 10:e66960.

Deans MR, Gibson JR, Sellitto C, Connors BW, Paul DL (2001) Synchronous Activity of Inhibitory Networks in Neocortex Requires Electrical Synapses Containing Connexin36. Neuron 31:477-485.

Domnisoru C, Kinkhabwala AA, Tank DW (2013) Membrane potential dynamics of grid cells. Nature 495:199-204.

Economo MN, White JA (2012) Membrane Properties and the Balance between Excitation and Inhibition Control Gamma-Frequency Oscillations Arising from Feedback Inhibition. PLoS Comput Biol 8:e1002354.

Fanselow EE, Richardson KA, Connors BW (2008) Selective, State-Dependent Activation of Somatostatin-Expressing Inhibitory Interneurons in Mouse Neocortex. Journal of Neurophysiology 100:2640-2652.

Frank LM, Brown EN, Wilson MA (2001) A comparison of the firing properties of putative excitatory and inhibitory neurons from CA1 and the entorhinal cortex. J Neurophysiol 86:20292040.

Fritschy J-M, Brünig I (2003) Formation and plasticity of GABAergic synapses: physiological mechanisms and pathophysiological implications. Pharmacology \& Therapeutics 98:299-323.

Fuchs EC, Neitz A, Pinna R, Melzer S, Caputi A, Monyer H (2016) Local and Distant Input Controlling Excitation in Layer II of the Medial Entorhinal Cortex. Neuron 89:194-208.

Fyhn M, Molden S, Witter MP, Moser EI, Moser M-B (2004) Spatial representation in the entorhinal cortex. Science 305:1258-1264.

Galarreta M, Hestrin S (1998) Frequency-dependent synaptic depression and the balance of excitation and inhibition in the neocortex. Nat Neurosci 1:587-594.

Gibson JR, Beierlein M, Connors BW (1999) Two networks of electrically coupled inhibitory neurons in neocortex. Nature 402:75-79.

Gittis AH, Nelson AB, Thwin MT, Palop JJ, Kreitzer AC (2010) Distinct Roles of GABAergic Interneurons in the Regulation of Striatal Output Pathways. J Neurosci 30:2223-2234.

Grosser S, Barreda FJ, Beed P, Schmitz D, Booker SA, Vida I (2021) Parvalbumin Interneurons Are Differentially Connected to Principal Cells in Inhibitory Feedback Microcircuits along the Dorsoventral Axis of the Medial Entorhinal Cortex. eNeuro 8 Available at: https://www.eneuro.org/content/8/1/ENEURO.0354-20.2020.

Hafting T, Fyhn M, Bonnevie T, Moser M-B, Moser EI (2008) Hippocampus-independent phase precession in entorhinal grid cells. Nature 453:1248-1252.

Hafting T, Fyhn M, Molden S, Moser MB, Moser EI (2005) Microstructure of a spatial map in the entorhinal cortex. Nature 436:801-806. 
Hjorth J, Blackwell KT, Kotaleski JH (2009) Gap Junctions between Striatal Fast-Spiking Interneurons Regulate Spiking Activity and Synchronization as a Function of Cortical Activity. J Neurosci 29:5276-5286.

Isaacson JS, Scanziani M (2011) How inhibition shapes cortical activity. Neuron 72:231-243.

Kawaguchi Y, Kubota Y (1997) GABAergic cell subtypes and their synaptic connections in rat frontal cortex. Cereb Cortex 7:476-486.

Kawaguchi Y, Kubota Y (1998) Neurochemical features and synaptic connections of large physiologically-identified GABAergic cells in the rat frontal cortex. Neuroscience 85:677-701.

Kecskés M, Henn-Mike N, Agócs-Laboda Á, Szőcs S, Petykó Z, Varga C (2020) Somatostatin expressing GABAergic interneurons in the medial entorhinal cortex preferentially inhibit layer III-V pyramidal cells. Commun Biol 3:1-13.

Keeley S, Fenton AA, Rinzel J (2017) Modeling fast and slow gamma oscillations with interneurons of different subtype. J Neurophysiol 117:950-965.

Kepecs A, Fishell G (2014) Interneuron cell types are fit to function. Nature 505:318-326.

Kitamura K, Judkewitz B, Kano M, Denk W, Häusser M (2008) Targeted patch-clamp recordings and single-cell electroporation of unlabeled neurons in vivo. Nat Methods 5:61-67.

Kohus Z, Káli S, Rovira-Esteban L, Schlingloff D, Papp O, Freund TF, Hájos N, Gulyás AI (2016) Properties and dynamics of inhibitory synaptic communication within the $\mathrm{CA} 3$ microcircuits of pyramidal cells and interneurons expressing parvalbumin or cholecystokinin. The Journal of Physiology 594:3745-3774.

Kraushaar U, Jonas P (2000) Efficacy and Stability of Quantal GABA Release at a Hippocampal Interneuron-Principal Neuron Synapse. J Neurosci 20:5594-5607.

Kubota Y, Karube F, Nomura M, Kawaguchi Y (2016) The Diversity of Cortical Inhibitory Synapses. Front Neural Circuits o Available at: https://www.frontiersin.org/articles/10.3389/fncir.2016.00027/full [Accessed July 20, 2021].

Kwan AC, Dan Y (2012) Dissection of Cortical Microcircuits by Single-Neuron Stimulation In Vivo. Current Biology 22:1459-1467.

Ma Y, Hu H, Agmon A (2012) Short-Term Plasticity of Unitary Inhibitory-to-Inhibitory Synapses Depends on the Presynaptic Interneuron Subtype. J Neurosci 32:983-988.

Maccaferri G, Roberts JD, Szucs P, Cottingham CA, Somogyi P (2000) Cell surface domain specific postsynaptic currents evoked by identified GABAergic neurones in rat hippocampus in vitro. J Physiol 524 Pt 1:91-116.

Mann EO, Paulsen O (2007) Role of GABAergic inhibition in hippocampal network oscillations. Trends in Neurosciences 30:343-349.

Markram H, Tsodyks M (1996) Redistribution of synaptic efficacy: A mechanism to generate infinite synaptic input diversity from a homogenous population of neurons without changing absolute synaptic efficacies. Journal of Physiology-Paris 90:229-232. 
Martínez JJ, Rahsepar B, White JA (2017) Anatomical and Electrophysiological Clustering of Superficial Medial Entorhinal Cortex Interneurons. eNeuro 4 Available at: https://www.eneuro.org/content/4/5/ENEURO.0263-16.2017.

Miao C, Cao Q, Moser M-B, Moser EI (2017) Parvalbumin and Somatostatin Interneurons Control Different Space-Coding Networks in the Medial Entorhinal Cortex. Cell 171:507-521.e17.

Motanis H, Seay MJ, Buonomano DV (2018) Short-Term Synaptic Plasticity as a Mechanism for Sensory Timing. Trends in Neurosciences 41:701-711.

Okun M, Lampl I (2008) Instantaneous correlation of excitation and inhibition during ongoing and sensory-evoked activities. Nat Neurosci 11:535-537.

Pastoll H, Solanka L, van Rossum MCW, Nolan MF (2013) Feedback Inhibition Enables ThetaNested Gamma Oscillations and Grid Firing Fields. Neuron 77:141-154.

Pelkey KA, Chittajallu R, Craig MT, Tricoire L, Wester JC, McBain CJ (2017) Hippocampal GABAergic Inhibitory Interneurons. Physiological Reviews 97:1619-1747.

Pfeffer CK, Xue M, He M, Huang ZJ, Scanziani M (2013) Inhibition of inhibition in visual cortex: the logic of connections between molecularly distinct interneurons. Nat Neurosci 16:1068-1076.

Reifenstein ET, Kempter R, Schreiber S, Stemmler MB, Herz AVM (2012) Grid cells in rat entorhinal cortex encode physical space with independent firing fields and phase precession at the single-trial level. PNAS 109:6301-6306.

Rudy B, Fishell G, Lee S, Hjerling-Leffler J (2011) Three groups of interneurons account for nearly $100 \%$ of neocortical GABAergic neurons. Developmental Neurobiology 71:45-61.

Sasaki T, Leutgeb S, Leutgeb JK (2015) Spatial and memory circuits in the medial entorhinal cortex. Curr Opin Neurobiol 32:16-23.

Shipston-Sharman O, Solanka L, Nolan MF (2016) Continuous attractor network models of grid cell firing based on excitatory-inhibitory interactions. The Journal of Physiology 594:65476557.

Song S, Sjöström PJ, Reigl M, Nelson S, Chklovskii DB (2005) Highly Nonrandom Features of Synaptic Connectivity in Local Cortical Circuits. PLOS Biology 3:e68.

Stimberg M, Goodman DFM, Brette R, Pittà MD (2019) Modeling Neuron-Glia Interactions with the Brian 2 Simulator. In: Computational Glioscience (De Pittà M, Berry H, eds), pp 471505 Springer Series in Computational Neuroscience. Cham: Springer International Publishing. Available at: https://doi.org/10.1007/978-3-030-00817-8_18.

Szabó GG, Holderith N, Gulyás AI, Freund TF, Hájos N (2010) Distinct synaptic properties of perisomatic inhibitory cell types and their different modulation by cholinergic receptor activation in the $\mathrm{CA} 3$ region of the mouse hippocampus. European Journal of Neuroscience 31:2234-2246.

Tang Q, Burgalossi A, Ebbesen CL, Ray S, Naumann R, Schmidt H, Spicher D, Brecht M (2014) Pyramidal and Stellate Cell Specificity of Grid and Border Representations in Layer 2 of Medial Entorhinal Cortex. Neuron 84:1191-1197. 
Taniguchi H, He M, Wu P, Kim S, Paik R, Sugino K, Kvitsani D, Fu Y, Lu J, Lin Y, Miyoshi G, 845 Shima Y, Fishell G, Nelson SB, Huang ZJ (2011) A Resource of Cre Driver Lines for Genetic

846 Targeting of GABAergic Neurons in Cerebral Cortex. Neuron 71:995-1013.

847 Tiesinga P, Sejnowski TJ (2009) Cortical Enlightenment: Are Attentional Gamma Oscillations 848 Driven by ING or PING? Neuron 63:727-732.

Tikidji-Hamburyan RA, Canavier CC (2020) Shunting Inhibition Improves Synchronization in Heterogeneous Inhibitory Interneuronal Networks with Type 1 Excitability Whereas Hyperpolarizing Inhibition Is Better for Type 2 Excitability. eNeuro 7 Available at: https://www.eneuro.org/content/7/3/ENEURO.0464-19.2020.

Tikidji-Hamburyan RA, Martínez JJ, White JA, Canavier CC (2015) Resonant Interneurons Can Increase Robustness of Gamma Oscillations. J Neurosci 35:15682-15695.

Tremblay R, Lee S, Rudy B (2016) GABAergic Interneurons in the Neocortex: From Cellular Properties to Circuits. Neuron 91:260-292.

Urban-Ciecko J, Barth AL (2016) Somatostatin-expressing neurons in cortical networks. Nat Rev Neurosci 17:401-409.

Wehr M, Zador AM (2003) Balanced inhibition underlies tuning and sharpens spike timing in auditory cortex. Nature 426:442-446.

Yavorska I, Wehr M (2016) Somatostatin-Expressing Inhibitory Interneurons in Cortical Circuits. Front Neural Circuits o Available at: https://www.frontiersin.org/articles/10.3389/fncir.2016.00076/full\#B83.

Yi F, Garrett T, Deisseroth K, Haario H, Stone E, Lawrence JJ (2021) Septohippocampal transmission from parvalbumin-positive neurons features rapid recovery from synaptic depression. Sci Rep 11:2117.

Zariwala HA, Madisen L, Ahrens KF, Bernard A, Lein ES, Jones AR, Zeng H (2011) Visual tuning properties of genetically identified layer $2 / 3$ neuronal types in the primary visual cortex of cretransgenic mice. Front Syst Neurosci 4:162. 


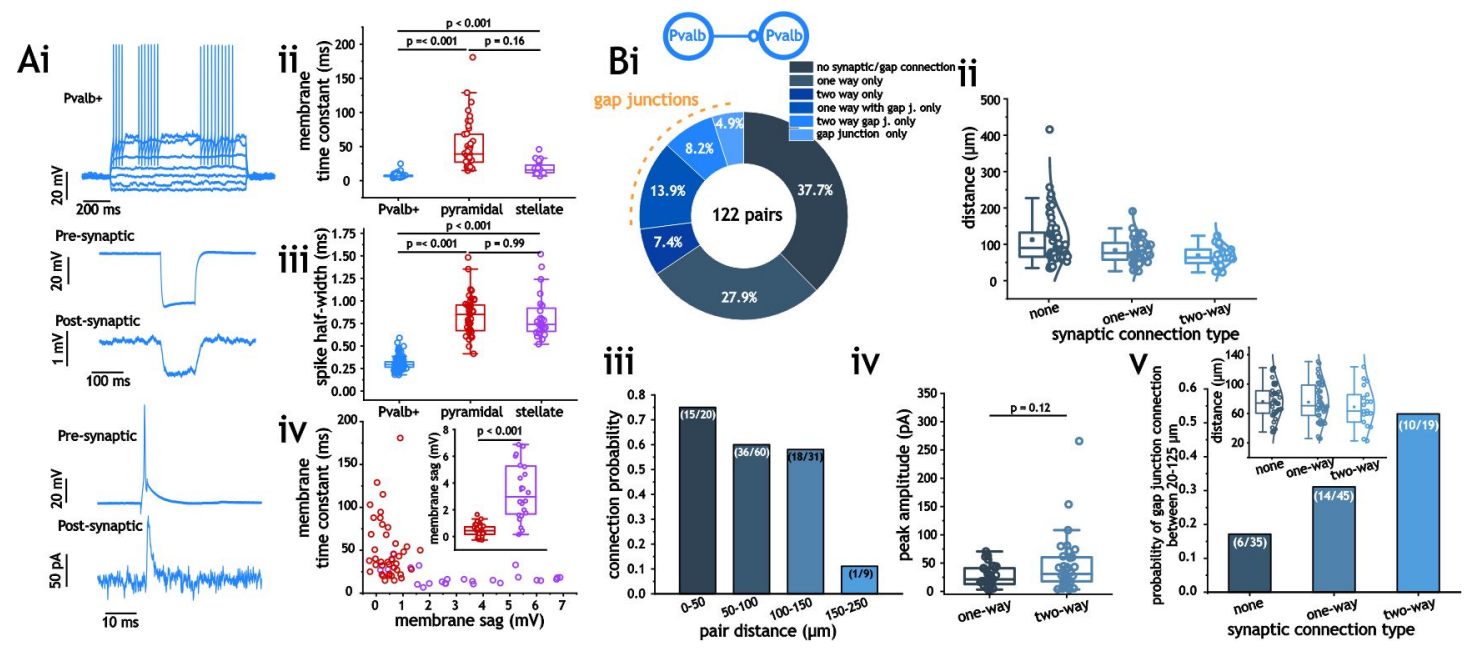



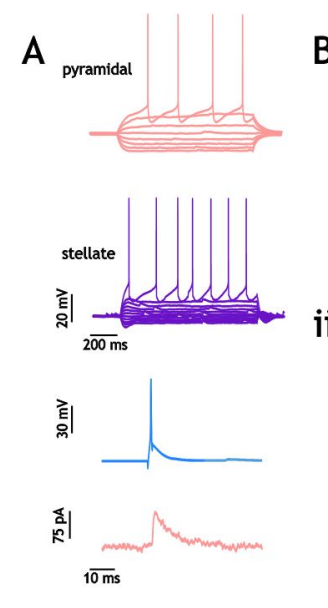
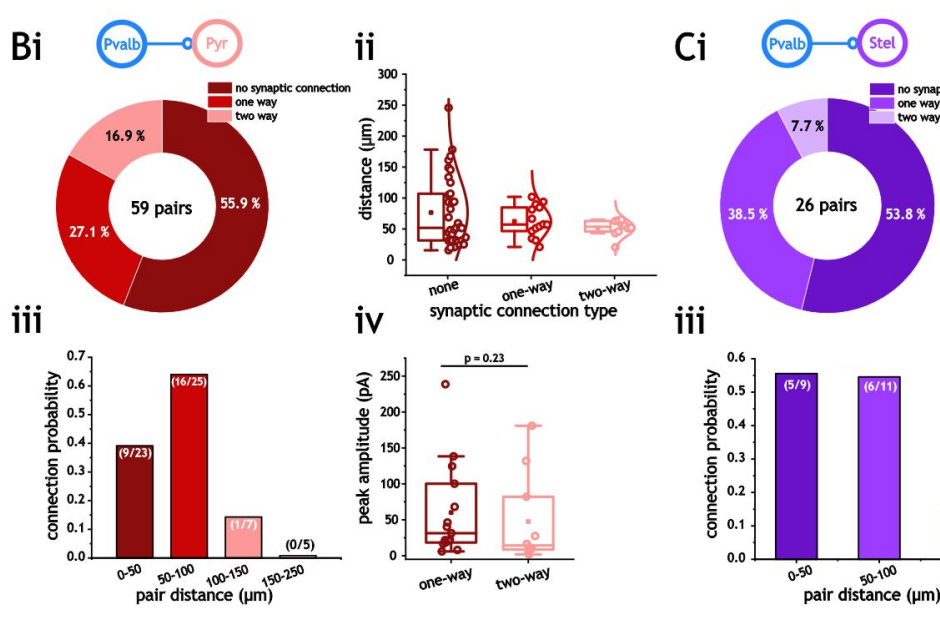

iii

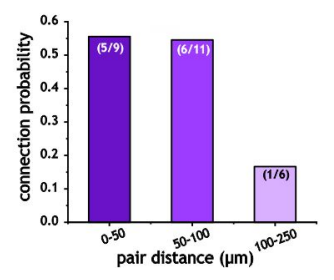

ii

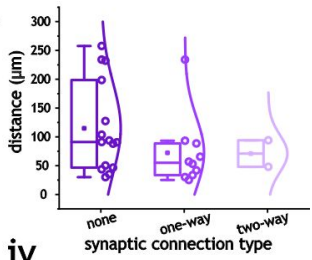

iv

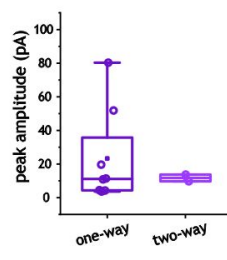




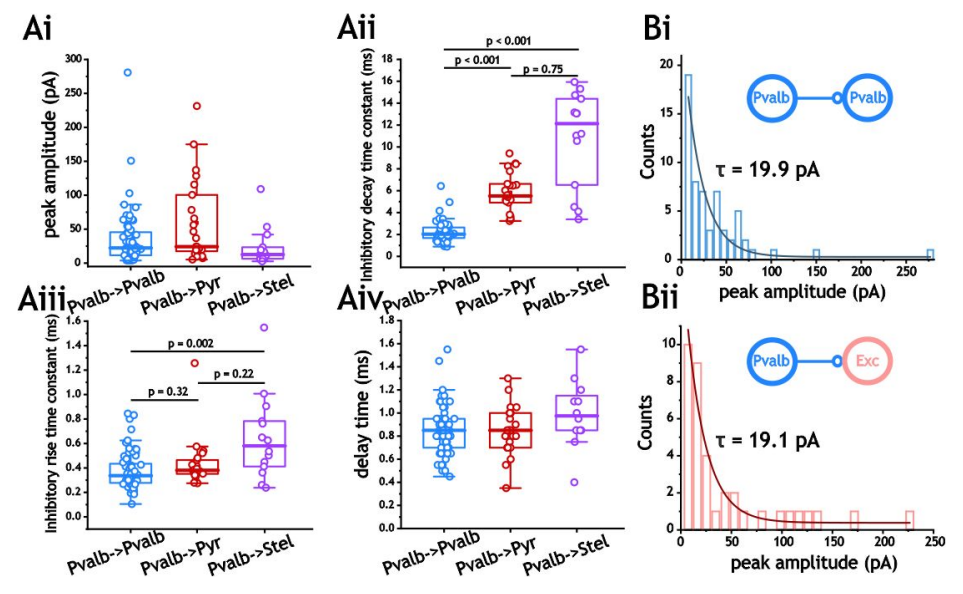



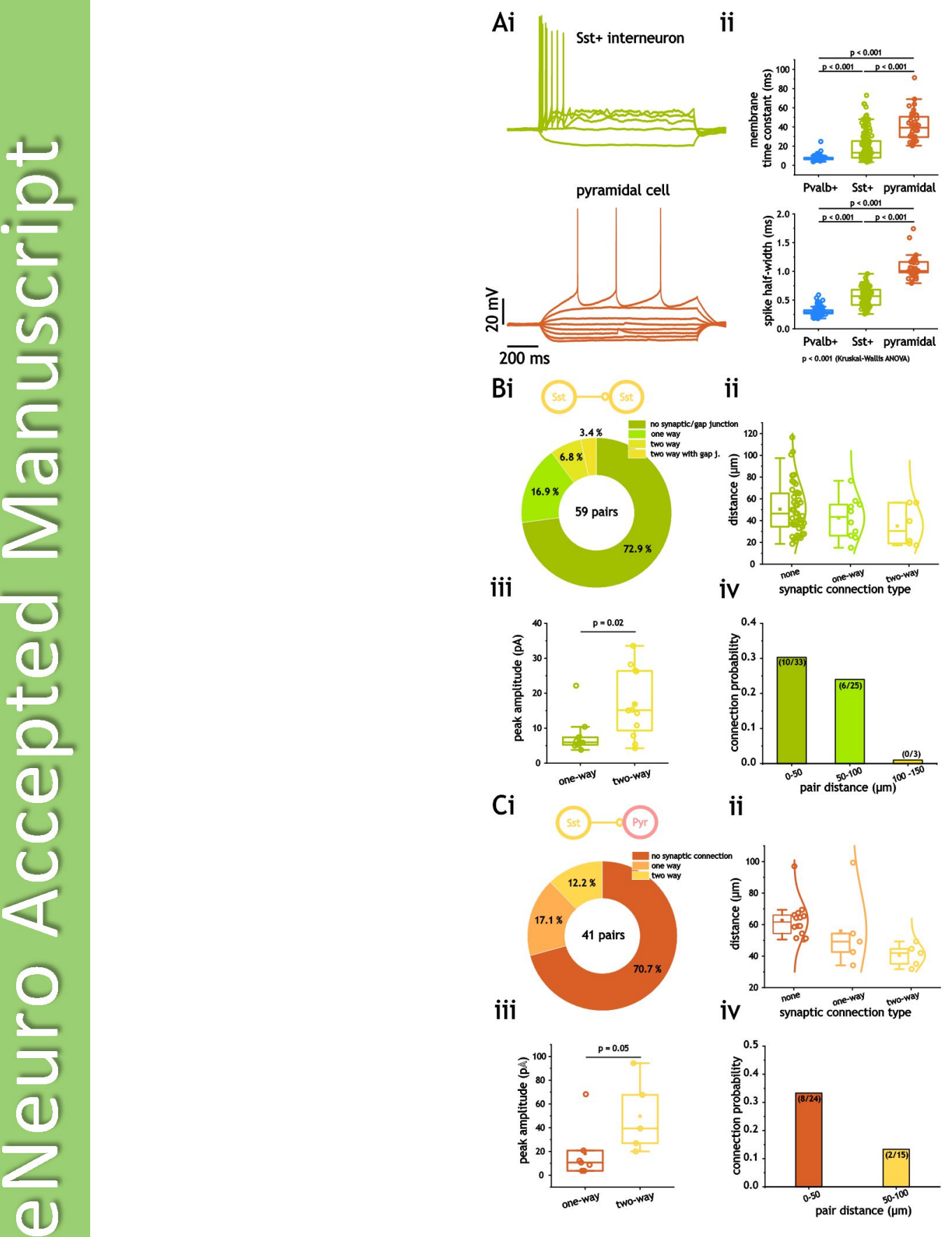

$\mathrm{Ci}$
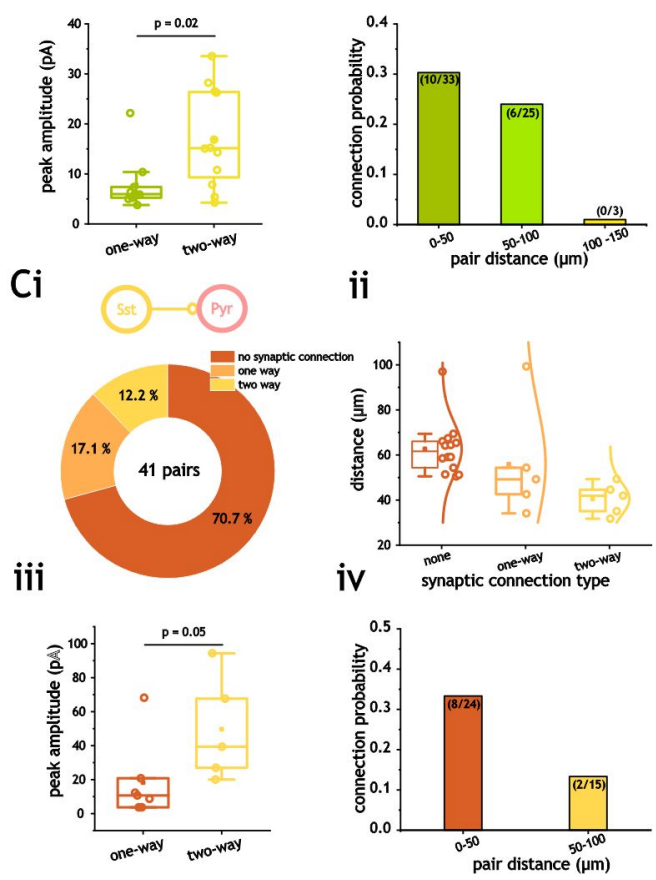


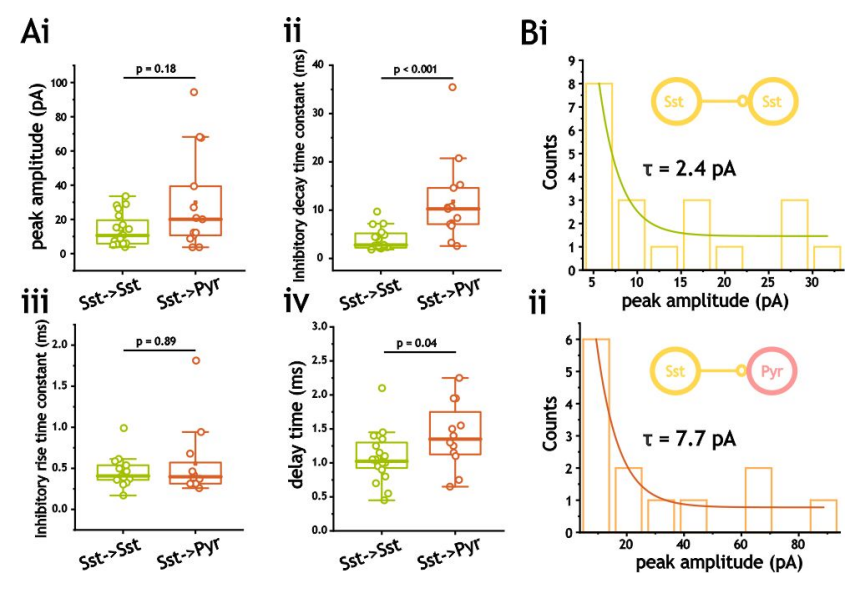



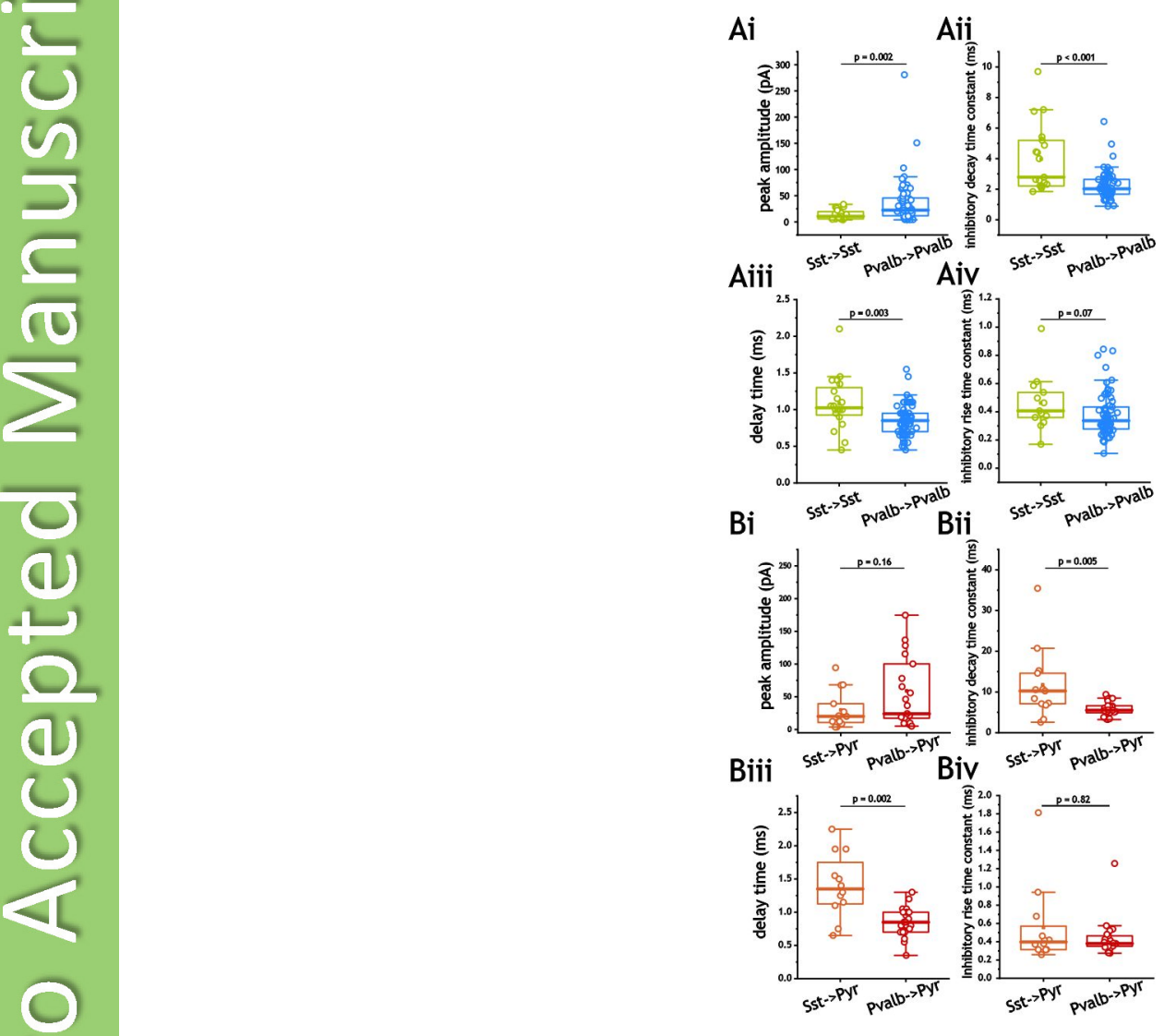


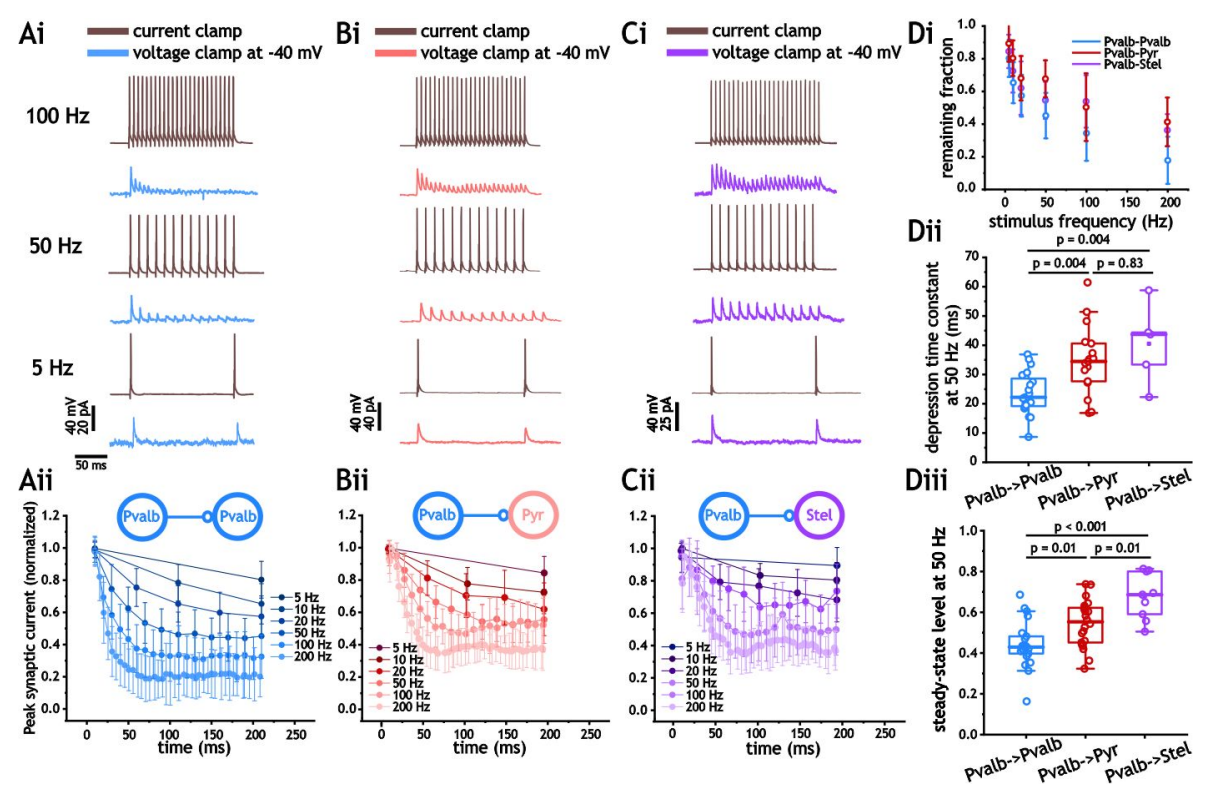




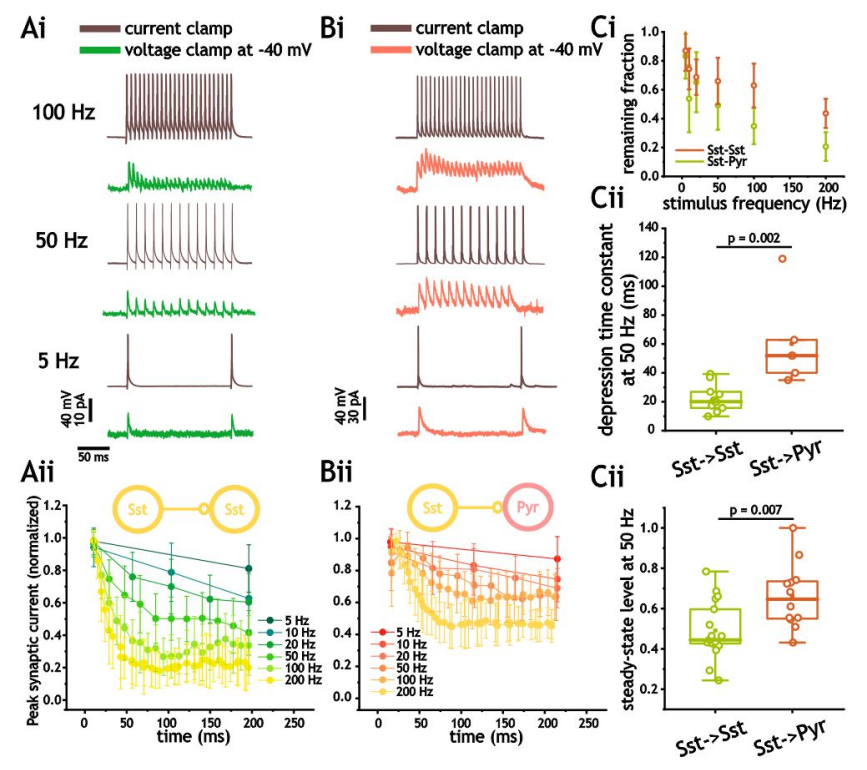




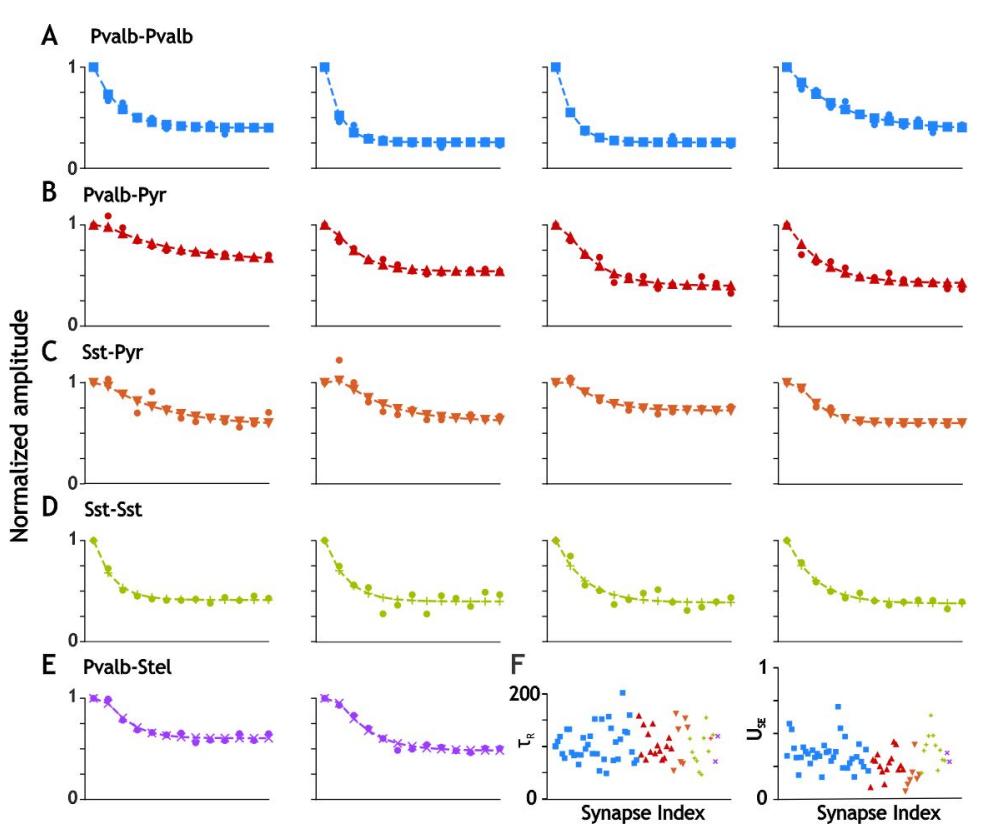


Table 1

\begin{tabular}{|l|l|l|l|l|l|}
\hline & PV-PV $(n=36)$ & PV-PYR (n=15) & PV-STL $(n=2)$ & SST-PYR (n=7) & SST-SST (n=11) \\
\hline$U_{S E}$ & $0.345 \pm 0.019$ & $0.261 \pm 0.023$ & $0.317 \pm 0.024$ & $0.183 \pm 0.040$ & $0.378 \pm 0.37$ \\
& $(0.166,0.702)$ & $(0.087,0.433)$ & $(0.284,0.350)$ & $(0.061,0.415)$ & $(0.197,0.636)$ \\
\hline \multirow{2}{*}{$\tau_{\mathrm{r}}$} & $105.4 \pm 5.5$ & $104.4 \pm 6.6$ & $96.3 \pm 17.0$ & $112.2 \pm 15.9$ & $96.4 \pm 9.4$ \\
& $(49.7,202.9)$ & $74.9,158.8)$ & $(72.2,120.4)$ & $(55.2,163.8)$ & $(47.3,155.5)$ \\
\hline
\end{tabular}

Synaptic Depression Model Parameter Statistics. The mean value and the standard error of the mean are given for each parameter value, with $\mathrm{n}$ indicating the number of data sets that fit the $\mathrm{R}^{2}$ criterion given in the methods and were included in Figure $9 \mathrm{~F}$ and this table. 